\title{
Viabilidade econômica do cultivo de videira Niágara Rosada
}

Economic feasibility of grapevine Niagara Rosada production

\author{
Meyriele Pires de Camargo ${ }^{1 *}$; Caroline Rabelo Costa
}

\author{
${ }^{1}$ Escola Superior de Agricultura "Luiz de Queiroz", Universidade de São Paulo - Engenheira Agrônoma, \\ Mestre em Fitopatologia - Departamento de Fitopatologia e Nematologia, Av. Pádua Dias, 11, CEP 13418- \\ 200, Piracicaba (SP), Brasil \\ 2 PECEGE - Engenheira Agrônoma, Doutora em Fitopatologia - Rua Alexandre Herculano, 120, sala T4 \\ Vila Monteiro, CEP 13418-445, Piracicaba (SP), Brasil
}

\section{Resumo}

O estado de São Paulo é o terceiro maior produtor de uvas do Brasil e o maior produtor nacional de uvas de mesa, sendo a variedade Niágara Rosada (Vitis labrusca) a mais plantada no estado. O objetivo do trabalho foi verificar a viabilidade econômica do cultivo de Niágara Rosada. O projeto foi dimensionado para uma área de três hectares implantada no município de Piracicaba, SP. As plantas foram conduzidas no sistema em espaldeira em uma densidade de 5000 plantas ha-1 ${ }^{-1}$ O fluxo de caixa foi dimensionado para um período de 13 anos. Estimaram-se os custos para implantação e manutenção do vinhedo, financiamento bancário, pagamento do Fundo de Apoio ao Trabalhador Rural [Funrural] e o custo de oportunidade da terra. A taxa mínima de atratividade [TMA] foi fixada em $11,45 \%$ e os indicadores econômicos calculados foram Valor Presente Líquido [VPL], Taxa Interna de Retorno [TIR], payback simples, payback descontado e relação benefício-custo. Obtiveram-se valores positivos de VPL $(R \$ 398.951,36)$ e relação custo-benefício $(1,81)$. A TIR foi estimada em $27,34 \%$, superior à TMA. Os valores de payback simples e descontado foram de cinco anos e de seis anos, respectivamente, indicando que o tempo de retorno do capital inicial investido foi inferior ao período do projeto. Os indicadores econômicos estimados constataram a viabilidade financeira do empreendimento em análise.

Palavras-chave: Vitis labrusca, custo de produção, VPL, TIR, payback

\begin{abstract}
São Paulo State is the third largest grapevine producer in Brazil and the largest national producer of table grapes. Niagara Rosada (Vitis labrusca) is the most planted cultivar in the State. This study aimed to verify the economic feasibility of Niagara Rosada production. The project was designed for an area of tree hectares to be implemented in Piracicaba, SP. Plants were conducted in vertical trellis system with 5000 plants ha- $^{-1}$. The cash flow was dimensioned for a period of 13 years. Costs with implantation and maintenance of the vineyard, bank financing, payment of the Rural Worker Support Fund, and the opportunity cost of land were estimated. The minimum acceptable rate of return [MARR] used was $11.45 \%$. The economic indicators calculated were Net Present Value [NPV], Internal Rate of Return [IRR], simple payback, discounted payback, and benefit-cost ratio. Positive values of NPV (R\$398,951.36) and benefit-cost ratio (1.81) were obtained. The IRR estimated was $27.34 \%$, higher than the MARR. The simple payback and the discounted payback were five years and six years, respectively, indicating that the period of returning the invested capital was lower than the project period. The estimated economic indicators demonstrated the financial feasibility of the project.
\end{abstract}

Keywords: Vitis labrusca, production cost, NPV, IRR, payback

\footnotetext{
*Autor correspondente:<meyrielecamargo@usp.br>

Enviado: 11 mar. 2017

Aprovado: 04 maio 2017
} 


\section{Introdução}

A vitivinicultura é uma atividade relevante no Brasil, realizada em diferentes regiões do país. Devido à grande dependência de mão-de-obra, os plantios de uva contribuem na geração de novos empregos e no desenvolvimento das regiões produtoras (EMBRAPA, 2013a). A vitivinicultura brasileira ocupou uma área de 79.592 ha e apresentou produção de 1.507 .419 t em 2015. O estado de São Paulo é o terceiro maior produtor de uvas do País, com 9,83\% da área plantada e 9,42\% da produção total, superado apenas pelo Rio Grande do Sul e Pernambuco (IBGE, 2016a). São Paulo é o maior produtor nacional de uvas de mesa (Oliveira et al., 2008; Silva et al., 2008) e a variedade Niágara Rosada é a mais plantada no Estado (Cato et al., 2005; Manica e Pommer, 2006).

A variedade Niágara Rosada pertence à espécie Vitis labrusca e foi originada a partir de uma mutação da variedade Niágara Branca (Silva et al., 2006). As variedades pertencentes a espécie Vitis labrusca tendem a apresentar maior rusticidade e serem menos suscetíveis a doenças fúngicas em relação as variedades de uvas finas (Vitis vinifera), reduzindo os custos de produção. A Niágara Rosada é uma variedade de uva de mesa muito produzida em regiões tropicais, apresentando boa aceitação pelo consumidor no mercado brasileiro e um custo de produção relativamente baixo (EMBRAPA, 2003). É de fácil cultivo, muito produtiva e bem adaptada às condições paulistas. A produção da cultivar concentra-se nos meses de dezembro a fevereiro, período no qual também ocorre a maior parte da comercialização da produção. Apesar do mês de dezembro apresentar o maior pico de comercialização, os preços de venda costumam ser inferiores. Os maiores preços são verificados nos meses de julho a novembro, período de menor oferta do produto (Manica e Pommer, 2006).

Os custos de produção são dependentes de uma série de fatores como sistema de produção adotado, valor dos insumos agrícolas e mão de obra. Dentre os sistemas de condução mais utilizados no cultivo da uva, encontra-se o sistema em espaldeira. Neste modelo, as plantas são conduzidas verticalmente. O custo de instalação da espaldeira é inferior ao de outros sistemas, como a latada, e apresenta facilidade na realização de tratos culturais como podas e pulverizações (Miele; Mandelli, 2008; EMBRAPA, 2013b).

Em qualquer situação, o levantamento de custos de produção e a análise financeira de determinada atividade são essenciais para a tomada de decisão na implantação do projeto em análise. Na literatura, poucos estudos são encontrados 
abordando a rentabilidade do cultivo de videira (EMBRAPA, 2003; Kreuz et al., 2005; EMBRAPA, 2010; Bendlin e Souza, 2013; Cappello, 20141; Reis e Reis, 2016). A maior parte desses trabalhos são direcionados para o cultivo de uvas em sistemas de condução que não a espaldeira, e em regiões diferentes da analisada no presente estudo, no caso, em Piracicaba, SP. O município possui o seu próprio Escritório de Desenvolvimento Rural [EDR], e situa-se próximo ao EDR de Campinas, um dos mais importantes polos produtores de uvas de mesa do estado de São Paulo (IEA, 2017). Embora o cultivo de videira no EDR de Piracicaba seja incipiente, a exploração desta atividade pode ser uma alternativa atrativa aos agricultores da região, caso comprovada a sua rentabilidade financeira.

Diante do exposto, os objetivos do trabalho foram avaliar os custos de produção e a viabilidade econômica do cultivo da variedade Niágara Rosada em Piracicaba, São Paulo, por meio dos indicadores econômicos Valor Presente Líquido [VPL], Taxa Interna de Retorno [TIR], payback simples, payback descontado e relação benefício/custo.

\section{Material e Métodos}

O estudo foi realizado no município de Piracicaba, São Paulo, e constitui-se em uma pesquisa descritiva. O levantamento de custos de produção, incluindo todos os materiais, maquinário e equipamentos, foram obtidos por meio de pesquisas de mercado, atribuindo-se os valores de acordo com os verificados no estado de São Paulo no ano de 2016.

\section{Descrição da área, implantação e condução do vinhedo}

Simulou-se a implantação do vinhedo no município de Piracicaba, São Paulo. De acordo com a classificação climática de Koeppen, Piracicaba é caracterizada pelo clima temperado úmido com inverno seco e verão quente (Cwa). A precipitação média anual é de 1.328,1 mm e as temperaturas médias entre 10 a $30{ }^{\circ} \mathrm{C}$ (CEPAGRI, 2016).

Considerou-se o plantio em pequena propriedade e agricultura familiar, com área total cultivada de 3 ha. Foram adquiridas mudas da variedade Niágara Rosada enxertada sobre IAC766 Campinas a partir de viveiros registrados. Anteriormente ao plantio, aplicou-se cianamida hidrogenada a $5 \%$ para estimular a quebra de dormência

${ }^{1}$ Cappello, F.P. 2014. Análise comparativa do custo de produção e rentabilidade da uva 'Niágara Rosada' cultivada em diferentes regiões do Estado de São Paulo. Dissertação de Mestrado em Ciências. Universidade de São Paulo, Piracicaba, SP, Brasil 
das gemas. O plantio das mudas foi realizado no final de agosto de 2016. As plantas foram conduzidas no sistema de condução em espaldeira.

As especificações para implantação do sistema de condução foram baseadas nas recomendações de Maia e Camargo (2012). Assim, os ramos foram conduzidos verticalmente em três fio de arame, nas alturas de 1,0 m, 1,3 m e 1,6 m em relação à altura do solo. Mourões de eucalipto tratado de 2,20 m de comprimento e $8,0 \mathrm{~cm}$ de diâmetro foram posicionados a cada $6,0 \mathrm{~m}$ na linha. Nas cabeceiras de cada linha, foram utilizados mourões de 2,20 m de comprimento e 16,0 cm de diâmetro, nos quais os arames foram amarrados. O espaçamento utilizado foi de 2,0 m entre linhas e 1,0 m entre plantas, totalizando 5.000 plantas $\mathrm{ha}^{-1}$.

No primeiro ano, as plantas estavam em processo de formação. A condução das plantas foi realizada em um único braço. No segundo ano, realizou-se uma poda curta, com uma a duas gemas por ramo, realizada em final de julho de 2017. Durante a estação de crescimento, fez-se a poda verde das plantas, a qual incluiu desbrota, retirada de netos, gavinhas e brotos laterais. A partir deste ano, as plantas se tornaram produtivas, entretanto, apresentaram um rendimento limitado. Nos anos seguintes, a poda seca e a poda verde foram realizadas anualmente, no mesmo período e da mesma forma descrita anteriormente.

As recomendações de correção e adubação do solo foram realizadas de acordo com dados reais obtidos na análise de solo de uma propriedade localizada em Piracicaba, São Paulo. O pH em água foi próximo de 6,0, não havendo necessidade de aplicação de calcário. Entretanto, para reduzir a concentração de $\mathrm{H}+\mathrm{Al}^{2}$ e aumentar a participação de cálcio na Capacidade de Troca de Cátions [CTC] do solo, optou-se pela aplicação de gesso agrícola. A quantidade de gesso aplicada foi calculada para elevar a percentagem de cálcio para $60 \%$ na participação da CTC. Assim, foram adicionados 2,66 t ha ${ }^{-1}$ de gesso agrícola, aplicado a lanço, anteriormente ao plantio. Em seguida, fez-se uma gradagem profunda do solo e o sulcamento da área para o preparo das covas $(50 \mathrm{~cm} \times 50 \mathrm{~cm} \times 50 \mathrm{~cm})$. Para a correção do solo, também foram necessários $120 \mathrm{~kg} \mathrm{ha}^{-1}$ de superfosfato triplo, aplicados juntamente com a adubação de implantação.

A adubação de implantação e as adubações de produção nos anos subsequentes foram baseadas nas recomendações da Embrapa (2003) e Tecchio et al. (2012) para esta cultivar. A adubação de implantação foi realizada 10 dias antes do plantio, com a adição de $5.000 \mathrm{~kg} \mathrm{ha}^{-1}$ de esterco de galinha poedeira, $115 \mathrm{~kg} \mathrm{ha}^{-1} \mathrm{de}$

${ }^{2} \mathrm{H}+\mathrm{Al}$ refere-se aos íons $\mathrm{H}^{+}$(hidrogênio) e $\mathrm{Al}^{3+}$ (alumínio), os quais representam a acidez potencial do solo 
cloreto de potássio e $430 \mathrm{~kg} \mathrm{ha}^{-1}$ de superfosfato triplo. A adubação nitrogenada em cobertura foi realizada com sulfato de amônio, parcelada em duas vezes: $250 \mathrm{~kg} \mathrm{ha}^{-1}$ aos 30 dias após o plantio, e $250 \mathrm{~kg} \mathrm{ha}^{-1}$ aos 120 dias após o plantio.

A partir do segundo ano de implantação, iniciaram-se as adubações de produção. As quantidades de fertilizantes a serem utilizadas variaram de acordo com a meta de produtividade e a análise de solo. No segundo ano, a meta de produção foi estimada para valores inferiores a $13 \mathrm{t} \mathrm{ha}^{-1}$. As doses de sulfato de amônio, superfosfato triplo e cloreto de potássio foram $350 \mathrm{~kg} \mathrm{ha}^{-1}, 170 \mathrm{~kg} \mathrm{ha}^{-1}$ e $100 \mathrm{~kg} \mathrm{ha}^{-1}$, respectivamente. A adubação de produção foi parcelada em três vezes, da seguinte maneira: i. um mês antes da poda $(100 \%$ do fósforo e $50 \%$ da dose de potássio recomendada, juntamente com $2.500 \mathrm{~kg} \mathrm{ha}^{-1}$ de esterco de galinha poedeira); ii. ramos com duas a três folhas separadas (50\% da dose de nitrogênio) e; iii. bagas entre 0 tamanho chumbinho e meia baga (restante da dose de nitrogênio e potássio) (Embrapa, 2003; Tecchio et al., 2012).

No terceiro ano, a meta de produção foi estipulada entre 13 e $22 \mathrm{t} \mathrm{ha}^{-1}$. Assim, foram aplicados $2.500 \mathrm{~kg} \mathrm{ha}^{-1}$ de esterco de galinha poedeira, $500 \mathrm{~kg} \mathrm{ha}^{-1}$ de sulfato de amônio, $215 \mathrm{~kg} \mathrm{ha}^{-1}$ de superfosfato triplo, $130 \mathrm{~kg} \mathrm{ha}^{-1}$ de cloreto de potássio e 10 $\mathrm{kg} \mathrm{ha}^{-1}$ de ácido bórico. A adubação de produção foi parcelada em três momentos: $i$. um mês antes da poda ( $100 \%$ do fósforo, $50 \%$ da dose de potássio e todo o esterco e ácido bórico); ii. ramos com duas a três folhas separadas (50\% da dose de nitrogênio) e; iii. bagas entre o tamanho chumbinho e meia baga (restante da dose de nitrogênio e potássio). Esta mesma recomendação foi seguida nos anos subsequentes de produção, com exceção da aplicação de boro, realizada em intervalos a cada três anos (Embrapa, 2003; Tecchio et al., 2012).

Durante o ciclo da cultura, realizaram-se o controle de plantas daninhas pela capina mecânica (roçadeira) e química (herbicidas). O uso de herbicidas foi realizado a partir do segundo ano de implantação do vinhedo. Herbicidas foram aplicados nas linhas de plantio anteriormente à brotação das gemas e após a colheita (duas vezes por ciclo). No restante do ciclo de cultivo, realizou-se a capina das linhas de cultivo com roçadeira lateral, no intervalo de 25 a 30 dias (oito vezes por ciclo). Nas entrelinhas, o controle de plantas daninhas foi realizado por meio de capina mecanizada a cada 25 a 30 dias (oito vezes por ciclo).

Pulverizações com fungicidas foram usadas para o controle das principais doenças da videira: míldio, oídio, antracnose, ferrugem, requeima das folhas e podridões de cacho (Naves et al. 2012). As aplicações iniciaram-se logo após a 
brotação, fase de maior suscetibilidade da cultura a doenças, e foram realizadas até o final do ciclo de cultivo com atomizador acoplado ao trator. No primeiro ano, estimaram-se oito pulverizações no ciclo. Nos demais anos de produção, considerouse a realização de 16 pulverizações por ciclo.

As principais pragas da cultura da videira englobam formigas cortadeiras, cochonilhas e ácaros (Botton et al., 2012). O controle de formigas foi realizado com iscas granuladas durante todo o ciclo da cultura. Para o controle das demais pragas, realizou-se uma única pulverização por ciclo de cultivo com inseticidas específicos.

A partir do primeiro ano de produção, anteriormente à colheita, realizou-se a cobertura dos cachos para evitar danos provocados por insetos e animais. $\mathrm{O}$ número de dias da poda a colheita foi estimado em 120 dias. Assim, a poda foi planejada de maneira que a colheita fosse realizada em meados de novembro, em razão dos melhores preços de mercado para comercialização da fruta nesse período.

De acordo com o balanço hídrico de Piracicaba, São Paulo, verificou-se período de déficit hídrico entre os meses de abril a outubro (Figura 1). Portanto, optouse pelo uso de irrigação nos meses com escassez de chuvas.

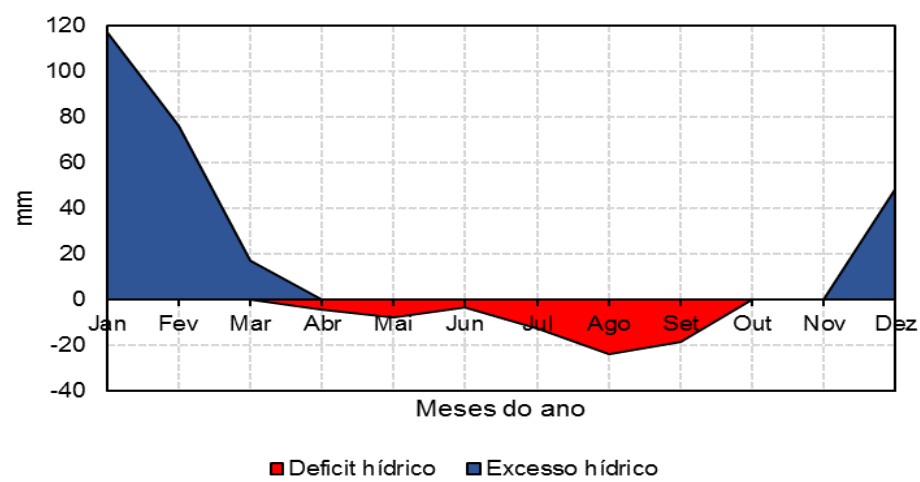

Figura 1. Extrato do balanço hídrico mensal do município de Piracicaba, São Paulo Fonte: NURMA (2016)

O sistema de irrigação por gotejamento foi dimensionado para uma área irrigada total de $92,0 \mathrm{~m} \times 326,0 \mathrm{~m}$, e área irrigada por planta de 1,0 m x 1,5 m. $\mathrm{O}$ espaçamento entre gotejadores foi de $0,75 \mathrm{~m}$ e a vazão de $1,6 \mathrm{~L} \mathrm{~h}^{-1}$ por gotejador. Considerou-se a evapotranspiração máxima da cultura de $4 \mathrm{~mm} \mathrm{dia}^{-1}$. Utilizou-se tubo gotejador autocompensante de $16 \mathrm{~mm}$ de diâmetro. A área irrigada foi dividida em 8 setores, contendo 12 linhas laterais por setor. O espaçamento entre linhas laterais foi de 2,0 m. Cada linha lateral apresentou comprimento de $163,0 \mathrm{~m}$ e foi composta por 217 gotejadores, totalizando uma vazão de $4,17 \mathrm{~m}^{3} \mathrm{~h}^{-1}$ por setor. O tempo de irrigação 
por setor foi de duas horas e o turno de trabalho de $16 \mathrm{~h} \mathrm{dia}^{-1}$. Dessa forma, o sistema foi construído para irrigar toda a área diariamente. A linha principal foi dimensionada para uma vazão de $4,17 \mathrm{~m}^{3} \mathrm{~h}^{-1}$, permitindo a irrigação de um setor por vez. A tubulação da linha principal foi constituída por tubo de polietileno de alta densidade com $32 \mathrm{~mm}$ de diâmetro e comprimento de 150,0 m. De acordo com o dimensionamento do sistema de irrigação, optou-se pela moto-bomba modelo KSB Hydrobloc C $1000 \mathrm{~N}$, com potência do motor de $1 \mathrm{CV}$.

Para reduzir os custos com mão de obra, o sistema de irrigação foi automatizado. No sexto ano após o plantio, todas as linhas de tubo-gotejadores foram substituídas. O custo com energia elétrica foi estimado para o consumo do motor de 1 $\mathrm{CV}$, no valor de $0,74 \mathrm{~kW}$. Esse valor, multiplicado pelo número diário de horas de funcionamento do motor (16 horas), resultou no consumo diário de energia, no valor de $11,84 \mathrm{~kW} \mathrm{~h}^{-1}$. Considerou-se que o ciclo de produção teve início em meados de julho e cerca de 120 dias de duração da poda à colheita. Com base no balanço hídrico de Piracicaba e no ciclo de produção da cultura, o número estimado de dias som o sistema de irrigação operando foi de 115 dias, resultando em um consumo de energia elétrica de 1361,6 $\mathrm{kW} \mathrm{h}^{-1}$ por safra.

\section{Estimativa de custos e receitas}

Os custos foram definidos com base em valores de mercado do ano 2016. A inflação foi considerada no estudo e foi estipulada com base nas séries históricas do Índice de Preços ao Consumidor Amplo [IPCA] do período de 2006 a 2016 (IBGE, 2016b). Assim, considerou-se um reajuste anual de 6,0\% no valor de cada uma das despesas de manutenção do vinhedo, bem como no custo de oportunidade da terra.

O custo de oportunidade da terra foi baseado nos valores de arrendamento na região (informação pessoal). Assim, no ano 1 , considerou-se o valor de $R \$ 4000,00$ ha $^{-1}$ ano $^{-1}$. No primeiro ano, também foram estimados os custos com a aquisição de mudas, correção do solo, adubação de formação das plantas, irrigação, instalação do sistema de sustentação das plantas, aquisição de máquinas e implementos agrícolas, materiais de uso no vinhedo e todas as operações a serem realizadas na área.

Nas operações foram incluídas operações manuais, mecanizadas contratadas e mecanizadas realizadas com o maquinário da propriedade. As operações contratadas foram a aplicação de gesso agrícola para a correção do solo, a gradagem pesada e o sulcamento da área. O valor dessas operações foi baseado no custo horário de um trator agrícola, disponibilizado pelo SOBRATEMA (2016). Nas 
operações mecanizadas com o maquinário da propriedade, foram incluídos os valores com mão de obra do operador e combustível. No controle de doenças e pragas, determinou-se o custo por aplicação com base nos custos com a utilização do atomizador (operador e combustível) e dos produtos fitossanitários.

O custo de manutenção anual com o sistema de irrigação foi estimado em 5\% do valor inicial investido. A taxa de energia elétrica foi determinada com base nos valores disponibilizados pela CPFL Energia (2016) para a área rural. $\mathrm{Na}$ taxa estimada, consideraram-se os custos com a transmissão e a distribuição da energia, somado aos encargos e tributos PIS (0,86\%) e COFINS (3,97\%). Pelo fato de ser área rural com exploração, considerou-se a isenção da tributação estadual pelo ICMS. Assim, o valor da tarifa no ano 1 foi de $\mathrm{R} \$ 0,3294$ por $\mathrm{kW} \mathrm{h}^{-1}$.

A depreciação foi calculada pelo método linear de depreciação para as máquinas e implementos agrícolas. Os bens considerados foram atomizador, pulverizador costal, trator, carreta, roçadeiras e perfurador de solo. O método linear considera que a depreciação é constante em cada período ao longo dos anos. Assim, o valor da diferença entre o investimento inicial e o valor residual do equipamento é dividido pela vida útil esperada, de acordo com a eq. (1) (Frizzone e Andrade Júnior, 2005).

$$
D=\frac{C-R}{n}
$$

onde, D: quota anual de depreciação $(R \$)$; C: valor inicial do bem $(R \$)$; R: valor residual $(R \$)$; $n$ : vida útil esperada do equipamento (anos).

A vida útil foi de 12 anos e o valor residual dos equipamentos e maquinário na ordem de $10,0 \%$ do valor inicial. O valor residual dos equipamentos e maquinário foi considerado como receita ao final do período de estudo.

A taxa de manutenção dos equipamentos e maquinário foi de $4,5 \%$ ao ano, calculada sobre o valor depreciado do equipamento em cada ano, de forma inversa. Assim, no segundo ano, o valor de manutenção correspondeu ao valor depreciado do equipamento previsto para o último ano. Para a manutenção no terceiro ano, foi considerado o valor depreciado do equipamento previsto para o penúltimo ano. $O$ mesmo raciocínio foi aplicado para os anos subsequentes.

Optou-se pelo financiamento de parte do projeto. O valor financiado foi de $R \$$ $420.000,00$, visando cobrir a maior parte das despesas de implantação e manutenção do vinhedo nos dois primeiros anos. O restante do investimento foi pago com capital 
próprio. A simulação do financiamento foi feita pelo Banco Nacional do Desenvolvimento [BNDES], para linha de crédito Programas Agrícolas Pronamp (BNDES, 2016). Na simulação, a taxa de juros foi de $8,5 \%$ ao ano, carência de 36 meses e prazo total do financiamento de 96 meses.

Os valores de produtividade tiveram como base o estudo realizado por Terra et al. (2003) e informações pessoais coletadas com produtores e em experimentos de campo com a cultivar Niágara Rosada. Consideraram-se valores crescentes de produtividade até o quinto ano, a partir do qual a produção atingiu o teto máximo, e manteve-se estável até o sétimo ano. A partir do ano 8, considerou-se uma pequena redução da produtividade em função da idade das plantas. O preço médio de venda da fruta foi estipulado com base nas séries históricas disponibilizadas pela HF Brasil (2017). Considerou-se a média dos valores de comercialização recebidos pelo produtor rural no estado de São Paulo para a cultivar Niágara, do período de novembro e dezembro de 2010 a 2016. A projeção dos valores de comercialização dos frutos foi definida de modo que os valores se mantivessem inalterados por três anos e acréscimos de $6,0 \%$ sobre o valor anterior ocorressem a cada triênio. Os valores de venda e as produtividades esperadas estão disponíveis na Tabela 1.

Tabela 1. Produtividade esperada $\left(\mathrm{kg}_{\text {planta-1 }}{ }^{-1}\right)$ e valor de comercialização $\left(\mathrm{R} \mathrm{kg}^{-1}\right) \mathrm{da}$ uva Niágara Rosada

\begin{tabular}{ccc}
\hline & Produtividade esperada & Valor de venda* $^{*}$ \\
\hline Ano 1 (2016) & ---- kg planta $^{-1}-----$ & - \\
Ano 2 (2017) & - & $4,75^{*}$ \\
Ano 3 (2018) & 2,0 & 4,75 \\
Ano 4 (2019) & 2,5 & 4,75 \\
Ano 5 (2020) & 3,0 & 5,03 \\
Ano 6 (2021) & 3,7 & 5,03 \\
Ano 7 (2022) & 3,7 & 5,03 \\
Ano 8 (2023) & 3,7 & 5,33 \\
Ano 9 (2024) & 3,6 & 5,33 \\
Ano 10 (2025) & 3,5 & 5,33 \\
Ano 11 (2026) & 3,4 & 5,62 \\
Ano 12 (2027) & 3,3 & 5,62 \\
Ano 13 (2028) & 3,2 & 5,62 \\
\hline
\end{tabular}

*Valores baseados na média dos preços de comercialização da cultivar Niágara no período de novembro e dezembro de 2010 a 2016 (HF Brasil, 2017)

Fonte: Dados originais da pesquisa

Sobre a receita bruta da produção em cada ano, subtraiu-se o pagamento do Fundo de Apoio ao Trabalhador Rural [Funrural], no valor de 2,1\%. 


\section{Indicadores econômicos}

O período de fluxo de caixa do projeto foi dimensionado para 13 anos. A uva é uma cultura perene e pode viver centenas de anos de idade e continuar a produzir (Keller, 2010). Por isso, o fluxo de caixa foi definido arbitrariamente para 13 anos. Para avaliar a rentabilidade e o retorno do investimento, foram utilizados os indicadores econômicos Valor Presente Líquido [VPL], Taxa Interna De Retorno [TIR], payback simples, payback descontado e relação benefício-custo.

A taxa mínima de atratividade [TMA] foi estimada com base na média dos valores anuais da taxa referencial do Sistema Especial de Liquidação e de Custódia [SELIC] dos anos de 2006 a 2016 (BCB, 2017). Assim, a TMA adotada foi de 11,45\%. Esse mesmo valor foi usado como a taxa de desconto para o cálculo do VPL e da relação benefício-custo.

O VPL é definido como a diferença entre o valor presente dos benefícios e o valor presente dos custos. Assim, os fluxos de caixa futuros durante a vida útil do projeto são descontados para o tempo inicial do projeto, a uma taxa de juros que representa o mínimo retorno para o capital, definida como a taxa de desconto. 0 critério de aceitação do projeto baseou-se na premissa de aceitá-lo caso o VPL obtido fosse positivo, ou seja, superior ao valor do investimento inicial. Dessa forma, o retorno financeiro do projeto saldaria o valor do investimento inicial, o que tornaria o projeto economicamente viável (Frizzone e Andrade Júnior, 2005). O VPL foi calculado pela eq. (2).

$$
\mathrm{VPL}=\sum_{\mathrm{t}=0}^{\mathrm{n}} \frac{\mathrm{FC} t}{(1+\mathrm{TMA})^{t}}
$$

onde, VPL: valor presente líquido; t: período (anos); n: vida útil do projeto; i: taxa de juros ou taxa de desconto; FC: Fluxo de caixa líquido.

A TIR corresponde a taxa de remuneração do capital investido, e representa a taxa de juros que torna o valor presente líquido nulo. Comparou-se o valor da TIR com a taxa mínima de atratividade e o projeto seria aceito caso a TIR fosse maior ou igual a taxa mínima de atratividade (Frizzone e Andrade Júnior, 2005). A TIR foi calculada pela igualdade da equação do cálculo do VPL à zero, conforme a eq. (3). 


$$
\mathrm{TIR}=\sum_{\mathrm{t}=0}^{\mathrm{n}} \frac{\mathrm{FC} t}{(1+\mathrm{TMA})^{t}}=0
$$

onde, t: período (anos); n: vida útil do projeto; i: Taxa de juros ou taxa de desconto; FC: Fluxo de caixa líquido.

O payback é obtido pelo somatório dos valores do fluxo de caixa até o tempo necessário para que o investimento seja totalmente amortizado pelos recebimentos. $\mathrm{Na}$ determinação do payback simples, não se levou em consideração o custo de oportunidade, a taxa de inflação, nem a taxa de juros. Ao contrário, para o cálculo do payback descontado, tanto o custo de oportunidade quanto a taxa de inflação e de juros foram levadas em consideração. Assim, na determinação do payback descontado, considerou-se a desvalorização monetária do capital no tempo (Assaf Neto e Lima, 2011).

A relação benefício-custo foi estimada pelo quociente entre os valores das entradas e os valores das saídas, ambos descontados da taxa de desconto estipulada. O projeto seria considerado viável quando o valor obtido fosse superior a 1 . Valores inferiores a 1 indicam que o projeto não cobriria o custo do capital e, portanto, deveria ser rejeitado (Mendonça et al., 2009). O índice foi calculado pela eq. (4).

$$
B / C=\sum_{i=0}^{n} \frac{\frac{R}{(1+r)^{n}}}{\frac{D}{(1+r)^{n}}}
$$

onde, $\mathrm{R}$ : receitas de cada período; $\mathrm{D}$ : despesas de cada período; r: taxa de desconto; $\mathrm{n}$ : vida útil do projeto.

\section{Resultados e Discussão}

$\mathrm{Na}$ composição de custos do ano 1, as maiores despesas foram com a aquisição de máquinas e implementos $(30,3 \%)$, seguida pela aquisição de mudas $(20,4 \%)$ e dos materiais para instalação do sistema de condução (16,2\%) (Tabela 2). Nos anos seguintes, os custos com a aquisição de mudas, máquinas agrícolas e sistema de condução foram nulos. No ano 2, o sombrite para a cobertura dos frutos representou metade dos custos totais (50,3\%). Neste mesmo ano, os juros provenientes do financiamento caracterizaram $17,3 \%$ dos custos, e as operações do vinhedo, nas quais estão inclusos os gastos com mão de obra e pulverizações, 15,0\%. 
No ano 3, os juros do financiamento e o item operações representaram mais de $65,0 \%$ do total das despesas. Do ano 4 em diante, a porcentagem dos juros do financiamento na composição dos custos de produção apresentou decréscimos. O financiamento foi liquidado no ano 8. A partir do ano 4, verificaram-se os maiores custos para o componente operações, provavelmente, pelo fato de estar incluso nesse item os gastos com mão de obra (Tabela 2).

Cappello ${ }^{3}$ determinou o custo de produção para a variedade Niágara Rosada e verificou que os custos com mão de obra foram os mais onerosos ao produtor, em razão, principalmente, dos tratos culturais, os quais exigem muita mão de obra.

O custo de oportunidade da terra variou de 3,6\% a 21,5\% das despesas, sendo mais representativo a partir do oitavo ano em diante, com cerca de $20,0 \%$ do custo de produção. As despesas com fertilizantes variaram de 1,7\% a 7,3\% do total dos custos. Os maiores gastos com irrigação foram observados no ano 1 , no qual foi realizada a instalação do sistema, e no ano 7, no qual foi necessária a troca de todos os tubos gotejadores da área. Nos demais anos, os gastos com a manutenção e energia elétrica do sistema de irrigação foram baixos, variando de $0,9 \%$ a $3,2 \%$ do total das despesas. A depreciação do maquinário variou de $3,7 \%$ a $8,1 \%$ dos custos, e a manutenção dos equipamentos de $0,2 \%$ a $3,7 \%$.

O custo com materiais envolveu a compra de tesouras de poda e de colheita, alceadores, fitas, grampos, equipamentos de proteção individual e caixas plásticas de colheita. O custo para aquisição desses materiais representou, no máximo, 3,1\% do custo total, o que foi observado no ano 2 , período no qual as caixas plásticas para a colheita dos frutos foram adquiridas. Os gastos com o pagamento do Funrural foram calculados de acordo com a receita bruta do ano. Os valores pagos compuseram $1,5 \%$ a $6,5 \%$ do total dos custos (Tabela 2 ).

A descrição detalhada dos itens e despesas gerais para implantação e manutenção da área encontram-se nas Tabelas 3, 4, 5, 6, 7 e 8.

${ }^{3}$ Cf. nota 1 
Tabela 2. Composição dos custos de produção (\%) do cultivo de uva Niágara Rosada para uma área de produção de 3 ha

\begin{tabular}{|c|c|c|c|c|c|c|c|}
\hline Despesas & Ano 1 & Ano 2 & Ano 3 & Ano 4 & Ano 5 & Ano 6 & Ano 7 \\
\hline & \multicolumn{7}{|c|}{--------------------------------------- \% ------------------------------------- } \\
\hline Mudas & 20,4 & - & - & - & - & - & - \\
\hline Adubação & 2,2 & 1,7 & 4,7 & 4,7 & 5,0 & 5,7 & 4,7 \\
\hline Irrigação & 8,4 & 0,9 & 2,0 & 2,1 & 2,2 & 2,4 & 23,6 \\
\hline Sistema de condução & 16,2 & - & - & - & - & - & - \\
\hline Maquinário & 30,3 & - & - & - & - & - & - \\
\hline Depreciação maquinário & - & 3,7 & 7,5 & 7,3 & 7,4 & 7,6 & 6,1 \\
\hline Manutençao maquinário & - & 0,2 & 0,8 & 1,1 & 1,4 & 1,8 & 1,7 \\
\hline Materiais & 0,8 & 3,1 & 1,2 & 1,3 & 2,0 & 2,2 & 2,9 \\
\hline Cobertura vinhedo & - & 50,3 & - & - & - & - & - \\
\hline Operações & 7,4 & 15,0 & 31,9 & 33,0 & 35,4 & 38,7 & 32,7 \\
\hline Juros Financiamento & 10,6 & 17,3 & 34,8 & 32,3 & 25,8 & 19,5 & 9,9 \\
\hline Custo de oportunidade da terra & 3,6 & 6,3 & 13,4 & 13,9 & 14,9 & 16,3 & 13,7 \\
\hline Funrural & - & 1,5 & 3,7 & 4,4 & 5,8 & 5,9 & 4,7 \\
\hline \multirow[t]{2}{*}{ Despesas } & Ano 8 & Ano 9 & Ano 10 & Ano 11 & Ano 12 & \multicolumn{2}{|c|}{ Ano 13} \\
\hline & \multicolumn{7}{|c|}{ 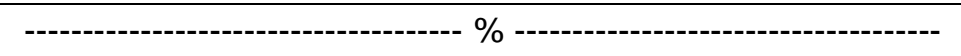 } \\
\hline Mudas & - & - & - & - & - & \multicolumn{2}{|l|}{-} \\
\hline Adubação & 6,5 & 7,0 & 7,0 & 7,1 & 7,2 & \multicolumn{2}{|l|}{7,3} \\
\hline Irrigação & 2,9 & 3,1 & 3,1 & 3,1 & 3,1 & \multicolumn{2}{|l|}{3,2} \\
\hline Sistema de condução & - & - & - & - & - & \multicolumn{2}{|l|}{-} \\
\hline Maquinário & - & - & - & - & - & \multicolumn{2}{|l|}{-} \\
\hline Depreciação maquinário & 8,0 & 8,1 & 7,7 & 7,3 & 7,0 & \multicolumn{2}{|l|}{6,7} \\
\hline Manutençao maquinário & 2,6 & 3,0 & 3,2 & 3,4 & 3,6 & \multicolumn{2}{|l|}{3,7} \\
\hline Materiais & 2,6 & 2,8 & 2,8 & 2,8 & 2,0 & \multicolumn{2}{|l|}{2,0} \\
\hline Cobertura vinhedo & - & - & - & - & - & \multicolumn{2}{|l|}{-} \\
\hline Operações & 45,9 & 49,1 & 49,5 & 49,7 & 50,6 & \multicolumn{2}{|l|}{51,0} \\
\hline Juros Financiamento & 5,6 & - & - & - & - & \multicolumn{2}{|l|}{-} \\
\hline Custo de oportunidade da terra & 19,3 & 20,6 & 20,8 & 20,9 & 21,3 & \multicolumn{2}{|l|}{21,5} \\
\hline Funrural & 6,5 & 6,3 & 5,9 & 5,7 & 5,3 & \multicolumn{2}{|l|}{4,7} \\
\hline
\end{tabular}

*Valores expressos em porcentagem em relação ao custo total

Fonte: Resultados originais da pesquisa 
Tabela 3. Descrição dos itens para implantação e manutenção de três hectares de uva Niágara Rosada no ano de cultivo 1

(continua)

\begin{tabular}{|c|c|c|c|c|}
\hline Descrição & Unidade & Quantidade & Valor unitário & Valor Total \\
\hline & & & \multicolumn{2}{|c|}{ 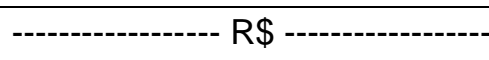 } \\
\hline Aquisição de mudas & 1 & 15000 & 4,50 & 67500,00 \\
\hline \multicolumn{5}{|l|}{ Adubação e correção do solo } \\
\hline gesso agrícola & $\mathrm{t}$ & 8 & 105,00 & 840,00 \\
\hline sulfato de amônio & $\mathrm{t}$ & 1,5 & 900,00 & 1350,00 \\
\hline superfosfato triplo & $\mathrm{t}$ & 1,65 & 1700,00 & 2805,00 \\
\hline cloreto de potássio & $\mathrm{t}$ & 0,345 & 1250,00 & 431,25 \\
\hline esterco de galinha poedeira & $\mathrm{t}$ & 15 & 120,00 & 1800,00 \\
\hline \multicolumn{5}{|l|}{ Sistema de irrigação } \\
\hline tubo gotejador $16 \mathrm{~mm}$ autocompensante & $\mathrm{m}$ & 15648 & 1,00 & 15648,00 \\
\hline tubo polietileno alta densidade $32 \mathrm{~mm}$ & $\mathrm{~m}$ & 150 & 0,70 & 105,00 \\
\hline Bomba KSB Hydrobloc C 1000 N (1CV) & 1 & 1 & 640,00 & 640,00 \\
\hline Conexões, filtros, válvulas, acessórios, controlador de irrigação, automação & - & 1 & 5000,00 & 5000,00 \\
\hline Casa alvenaria para bomba $(1,5 \times 1,0 \times 2,0)$ & 1 & 1 & 980,00 & 980,00 \\
\hline mão de obra instalação & - & 1 & 5000,00 & 5000,00 \\
\hline energia elétrica & $\mathrm{kW} \mathrm{h} \mathrm{h}^{-1}$ & 1361,6 & 0,33 & 448,51 \\
\hline \multicolumn{5}{|l|}{ Sitema de condução } \\
\hline arame galvanizado 14 BWG & $\mathrm{kg}$ & 1700 & 5,60 & 9520,00 \\
\hline arame galvanizado 6 BWG & $\mathrm{kg}$ & 100 & 5,35 & 535,00 \\
\hline mourão 2,2 mx8-10 cm & 1 & 2683 & 13,20 & 35415,60 \\
\hline mourão 2,5 mx14-16 cm & 1 & 184 & 40,80 & 7507,20 \\
\hline parafuso olhal 1/4"x200mm & 1 & 92 & 2,50 & 230,00 \\
\hline catraca & 1 & 92 & 4,90 & 450,80 \\
\hline
\end{tabular}


Tabela 3. Descrição dos itens para implantação e manutenção de três hectares de uva Niágara Rosada no ano de cultivo 1

(continua)

\begin{tabular}{|c|c|c|c|c|}
\hline Descrição & Unidade & Quantidade & Valor unitário & Valor Total \\
\hline & & & ---------------- P & 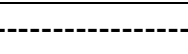 \\
\hline \multicolumn{5}{|l|}{ Maquinário } \\
\hline trator Agrale $42304 \times 4$ & 1 & 1 & 65000,00 & 65000,00 \\
\hline roçadeira RP 1500 Baldan & 1 & 1 & 7690,00 & 7690,00 \\
\hline roçadeira lateral a gasolina & 1 & 1 & 2089,00 & 2089,00 \\
\hline atomizador & 1 & 1 & 16350,00 & 16350,00 \\
\hline perfurador de solo PSMR 2.0 para trator & 1 & 1 & 3700,00 & 3700,00 \\
\hline Carreta de madeira Triton -2 ton $(2,40 \times 1,50 \times 0,60 m)$ & 1 & 1 & 4800,00 & 4800,00 \\
\hline pulverizador costal Jacto 20L & 1 & 1 & 265,00 & 265,00 \\
\hline enxada & 1 & 2 & 30,00 & 60,00 \\
\hline pá & 1 & 2 & 20,00 & 40,00 \\
\hline cavadeira manual & 1 & 2 & 48,00 & 96,00 \\
\hline \multicolumn{5}{|l|}{ Materiais } \\
\hline tesoura de poda & 1 & 6 & 30,00 & 180,00 \\
\hline tesoura de colheita & 1 & 6 & 26,00 & 156,00 \\
\hline alceador & 1 & 3 & 189,00 & 567,00 \\
\hline fita para alceador $11 \mathrm{~mm} \times 30 \mathrm{~m}$ & pct c/ 10 & 120 & 7,00 & 840,00 \\
\hline grampo para alceador 6/4b & pct c/ 4800 & 75 & 2,80 & 210,00 \\
\hline EPI completo aplicação de agrotóxicos & 1 & 3 & 196,00 & 588,00 \\
\hline \multicolumn{5}{|l|}{ Operações } \\
\hline aplicação de gesso & $\mathrm{R} \$ \mathrm{~h}^{-1}$ & 1 & 121,64 & 121,64 \\
\hline gradagem pesada & $R \$ h^{-1}$ & 2,9 & 121,64 & 352,76 \\
\hline demarcação da área e estaqueamento & d homem-1 & 2 & 80,00 & 160,00 \\
\hline sulcamento das covas & $R \$ h^{-1}$ & 3,33 & 121,64 & 405,06 \\
\hline
\end{tabular}


Tabela 3. Descrição dos itens para implantação e manutenção de três hectares de uva Niágara Rosada no ano de cultivo 1

(continua)

\begin{tabular}{|c|c|c|c|c|c|}
\hline Descrição & & Unidade & Quantidade & Valor unitário & Valor total \\
\hline & & & & -------------- F & 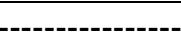 \\
\hline \multirow{2}{*}{ Adubação dos sulcos } & manual & d homem-1 & 6 & 80,00 & 480,00 \\
\hline & trator & $R \$ d^{-1}$ & 3 & 149,60 & 448,80 \\
\hline \multirow{2}{*}{ Plantio } & manual & d homem-1 & 10 & 80,00 & 800,00 \\
\hline & trator & $R \$ d^{-1}$ & 10 & 149,60 & 1496,00 \\
\hline \multirow{2}{*}{ Adubação de cobertura } & manual & d homem-1 & 3 & 80,00 & 240,00 \\
\hline & trator & $R \$ d^{-1}$ & 3 & 149,60 & 448,80 \\
\hline \multirow{2}{*}{ Instalação sistema de condução } & abertura covas $\mathrm{c} /$ perfurador de solo & $R \$ d^{-1}$ & 6 & 149,60 & 897,60 \\
\hline & instalação (mourões, fios de arame) & d homem-1 & 45 & 80,00 & 3600,00 \\
\hline \multirow{2}{*}{ Aplicação dormex } & trator & $\mathrm{R} \$ \mathrm{~h}^{-1}$ & 3,41 & 18,70 & 63,77 \\
\hline & produto & I & 18 & 111,00 & 1998,00 \\
\hline Tutoramento de plantas & manual & $\mathrm{d}$ homem-1 & 100 & 80,00 & 8000,00 \\
\hline \multirow{2}{*}{ Controle de doenças } & trator & $\mathrm{R} \$ \mathrm{~h}^{-1}$ & 27,28 & 18,70 & 510,14 \\
\hline & produto & aplicação & 8 & 66,49 & 531,92 \\
\hline \multirow{4}{*}{ Controle de pragas } & trator & $\mathrm{R} \$ \mathrm{~h}^{-1}$ & 3,41 & 18,70 & 63,77 \\
\hline & produto & aplicação & 1 & 45,00 & 45,00 \\
\hline & Fipronil-Iscas para formiga & $\mathrm{kg}$ & 6 & 20,80 & 124,80 \\
\hline & mão de obra iscas & d homem-1 & 1 & 80,00 & 80,00 \\
\hline \multirow{3}{*}{ Controle de plantas daninhas } & herbicida aplicação c/costal (2x) & d homem-1 & 10 & 80,00 & 800,00 \\
\hline & produto & aplicação & 2 & 78,00 & 156,00 \\
\hline & roçaderia manual nas linhas $(8 x)$ & $R \$ d^{-1}$ & 8 & 291,70 & 2333,60 \\
\hline Controle de plantas daninhas & roçadeira trator $(8 x)$ & $\mathrm{R} \$ \mathrm{~h}^{-1}$ & 22,64 & 18,70 & 423,37 \\
\hline TOTAL & & $\mathrm{R} \$$ & & & $283.418,38$ \\
\hline
\end{tabular}


Tabela 4. Descrição dos itens para manutenção de três hectares de uva Niágara Rosada no ano de cultivo 2

(continua)

\begin{tabular}{|c|c|}
\hline \multicolumn{2}{|l|}{ Descrição } \\
\hline \multicolumn{2}{|l|}{ Adubação de produção } \\
\hline \multicolumn{2}{|l|}{ sulfato de amônio } \\
\hline \multicolumn{2}{|l|}{ superfosfato triplo } \\
\hline \multicolumn{2}{|l|}{ cloreto de potássio } \\
\hline \multicolumn{2}{|c|}{ esterco de galinha poedeira } \\
\hline \multicolumn{2}{|l|}{ Irrigação } \\
\hline \multicolumn{2}{|l|}{ custo de manutenção } \\
\hline \multicolumn{2}{|l|}{ energia elétrica } \\
\hline \multicolumn{2}{|l|}{ Materiais } \\
\hline \multicolumn{2}{|c|}{ fita para alceador $11 \mathrm{~mm}$ x 30m } \\
\hline \multicolumn{2}{|c|}{ grampo para alceador 6/4b } \\
\hline \multirow{2}{*}{\multicolumn{2}{|c|}{$\begin{array}{l}\text { sombrite cobertura cachos colheita } \\
\text { caixas plásticas colheita }(18 \times 40 \times 60 \mathrm{~cm})\end{array}$}} \\
\hline & \\
\hline \multicolumn{2}{|l|}{ Operações } \\
\hline \multicolumn{2}{|l|}{ Adubação de produção } \\
\hline & trator + operador \\
\hline \multirow[t]{2}{*}{ Aplicação dormex } & trator \\
\hline & produto \\
\hline Tutoramento de plantas & manual \\
\hline Controle de doenças & trator \\
\hline & produto \\
\hline Controle de pragas & trator \\
\hline
\end{tabular}

Unidade

Quantidade

Valor unitário
$\mathrm{R} \$$

Valor Total

1061,80

$\mathrm{t} \quad 1,05$

954,00

974,16

$\mathrm{t} \quad 0,51$

0,3

1802,00

1325,00

421,35

127,20

1011,24

$\begin{array}{cccc}\text { anual } & 1 & 1300,00 & 1378,00 \\ \mathrm{~kW} \mathrm{~h}^{-1} & 1361,6 & 0,35 & 503,95\end{array}$

$\begin{array}{ccc}\text { pct c/ } 10 & 120 & 7,42 \\ \text { pct c/ } 4800 & 75 & 2,97 \\ \mathrm{~m}^{2} & 32107 & 3,17 \\ 1 & 300 & 17,00\end{array}$

943,82

235,96

101779,19

5100,00

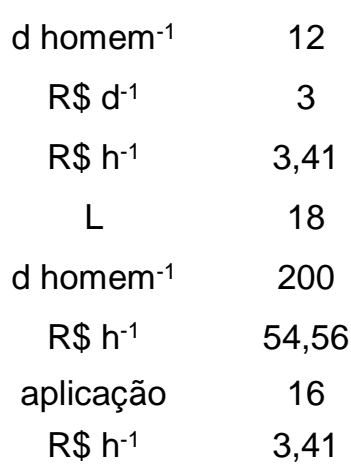

84,80

1078,66

158,58

504,27

19,82

71,65

117,66

2244,95

84,80

17977,60

19,82

1146,38

70,48

1195,33

19,82

71,65 
Tabela 4. Descrição dos itens para manutenção de três hectares de uva Niágara Rosada no ano de cultivo 2

(conclusão)

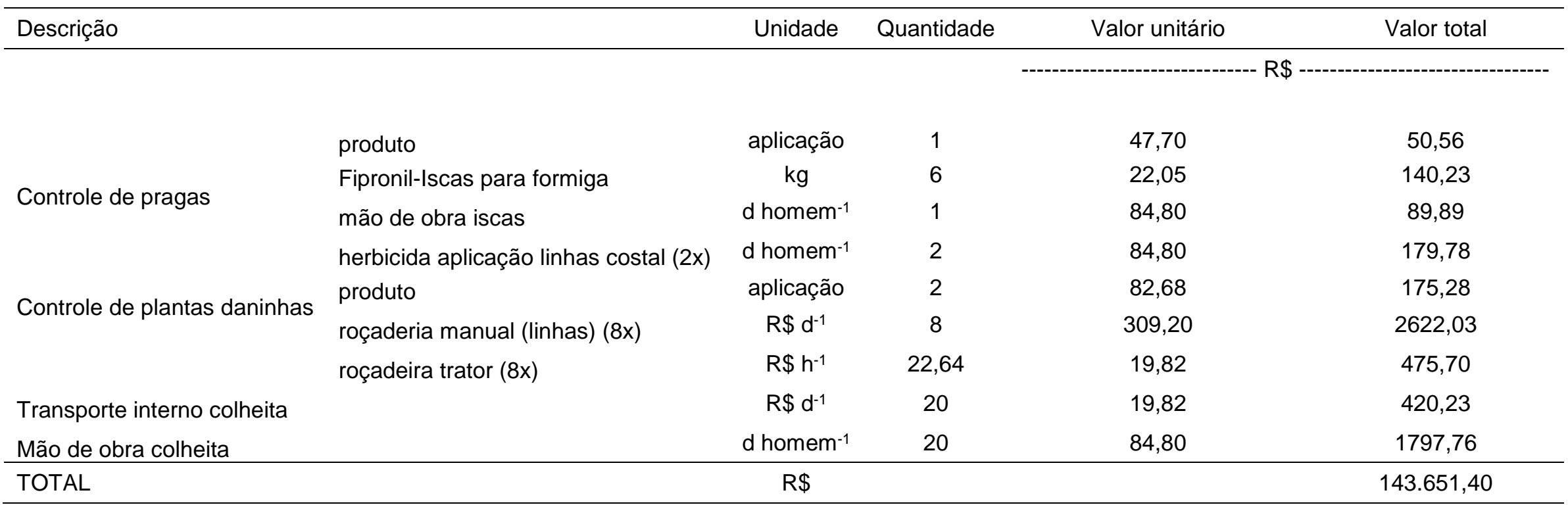


Tabela 5. Descrição dos itens para manutenção de três hectares de uva Niágara Rosada nos anos de cultivo 3, 4 e 5

(continua)

\begin{tabular}{|c|c|c|c|c|c|c|c|c|c|}
\hline \multirow{2}{*}{\multicolumn{2}{|c|}{ Descrição }} & \multirow[b]{2}{*}{ Unidade } & \multirow[b]{2}{*}{ Quantidade } & \multicolumn{2}{|c|}{ Ano 3} & \multicolumn{2}{|c|}{ Ano 4} & \multicolumn{2}{|c|}{ Ano 5} \\
\hline & & & & $\begin{array}{c}\text { Valor } \\
\text { unitário }\end{array}$ & $\begin{array}{l}\text { Valor } \\
\text { total }\end{array}$ & $\begin{array}{c}\text { Valor } \\
\text { unitário }\end{array}$ & $\begin{array}{l}\text { Valor } \\
\text { total }\end{array}$ & $\begin{array}{c}\text { Valor } \\
\text { unitário }\end{array}$ & $\begin{array}{l}\text { Valor } \\
\text { total }\end{array}$ \\
\hline \multicolumn{10}{|l|}{ Adubação de produção } \\
\hline sulfato de amônio & & $\mathrm{t}$ & 1,5 & 1071,91 & 1607,87 & 1136,23 & 1704,34 & 1204,40 & 1806,60 \\
\hline superfosfato triplo & & $\mathrm{t}$ & 0,645 & 2024,73 & 1305,95 & 2146,21 & 1384,31 & 2274,98 & 1467,36 \\
\hline \multicolumn{2}{|l|}{ cloreto de potássio } & $\mathrm{t}$ & 0,39 & 1488,77 & 580,62 & 1578,10 & 615,46 & 1672,78 & 652,38 \\
\hline \multicolumn{2}{|c|}{ Esterco de galinha poedeira } & $\mathrm{t}$ & 7,5 & 142,92 & 1071,91 & 151,50 & 1136,23 & 160,59 & 1204,40 \\
\hline \multicolumn{2}{|c|}{ Ãcido bórico } & $\mathrm{kg}$ & 30 & 4,77 & 143,10 & 0,0 & 0,0 & & \\
\hline \multicolumn{2}{|l|}{ custo de manutenção } & anual & 1 & 1460,68 & 1460,68 & 1548,32 & 1548,32 & 1641,22 & 1641,22 \\
\hline \multicolumn{2}{|l|}{ energia elétrica } & $\mathrm{kW} \mathrm{h}^{-1}$ & 1361,6 & 0,39 & 534,18 & 0,42 & 566,23 & 0,44 & 600,21 \\
\hline \multicolumn{10}{|l|}{ Materiais } \\
\hline \multicolumn{2}{|c|}{ fita para alceador $11 \mathrm{~mm} \times 30 \mathrm{~m}$} & pct c/10 & 120 & 8,34 & 1000,45 & 8,84 & 1060,48 & 9,37 & 1124,11 \\
\hline \multicolumn{2}{|c|}{ grampo para alceador $6 / 4 b$} & pct c/4800 & 75 & 3,33 & 250,11 & 3,53 & 265,12 & 3,75 & 281,03 \\
\hline \multicolumn{2}{|l|}{ Caixas plásticas colheita } & 1 & 30 & - & - & - & - & 21,47 & 643,95 \\
\hline \multicolumn{10}{|l|}{ Operações } \\
\hline \multirow[t]{2}{*}{ Adubação de produção } & manual & $\mathrm{d}_{\text {homem}}-1$ & 12 & 95,28 & 1143,38 & 101,00 & 1211,98 & 107,06 & 1284,70 \\
\hline & trator & $R \$ d^{-1}$ & 3 & 178,18 & 534,53 & 188,87 & 566,60 & 200,20 & 600,60 \\
\hline \multirow[t]{2}{*}{ Aplicação cianamida } & trator & $R \$ h^{-1}$ & 3,41 & 22,27 & 75,95 & 23,61 & 80,50 & 25,02 & 85,33 \\
\hline & produto & $L$ & 18 & 132,20 & 2379,65 & 140,13 & 2522,43 & 148,54 & 2673,77 \\
\hline Tutoramento de plantas & manual & $\mathrm{d}_{\text {homem-1 }}-1$ & 200 & 95,28 & 19056,26 & 101,00 & 20199,63 & 107,06 & 21411,61 \\
\hline
\end{tabular}


Tabela 5. Descrição dos itens para manutenção de três hectares de uva Niágara Rosada nos anos de cultivo 3, 4 e 5

(conclusão)

\begin{tabular}{|c|c|c|c|c|c|c|c|c|c|}
\hline \multirow[b]{2}{*}{ Descrição } & & \multirow[b]{2}{*}{ Unidade } & \multirow[b]{2}{*}{ Quantidade } & \multicolumn{2}{|c|}{ Ano 3} & \multicolumn{2}{|c|}{ Ano 4} & \multicolumn{2}{|c|}{ Ano 5} \\
\hline & & & & $\begin{array}{c}\text { Valor } \\
\text { unitário }\end{array}$ & $\begin{array}{l}\text { Valor } \\
\text { total }\end{array}$ & $\begin{array}{c}\text { Valor } \\
\text { unitário }\end{array}$ & $\begin{array}{l}\text { Valor } \\
\text { total }\end{array}$ & $\begin{array}{c}\text { Valor } \\
\text { unitário }\end{array}$ & $\begin{array}{l}\text { Valor } \\
\text { total }\end{array}$ \\
\hline & & & & & & -- & Q - - & --------- & ------------- \\
\hline \multirow[t]{4}{*}{ Controle de doenças } & trator & $\mathrm{R} \$ \mathrm{~h}^{-1}$ & 54,56 & 22,27 & 1215,16 & 23,61 & 1288,07 & 25,02 & 1365,35 \\
\hline & produto & aplicação & 16 & 79,19 & 1267,05 & 83,94 & 1343,07 & 88,98 & 1423,66 \\
\hline & trator & $\mathrm{R} \$ \mathrm{~h}^{-1}$ & 3,41 & 22,27 & 75,95 & 23,61 & 80,50 & 25,02 & 85,33 \\
\hline & produto & aplicação & 1 & 53,60 & 53,60 & 56,81 & 56,81 & 60,22 & 60,22 \\
\hline \multirow[t]{3}{*}{ Controle de pragas } & $\begin{array}{l}\text { Fipronil - } \\
\text { Isca formiga }\end{array}$ & $\mathrm{kg}$ & 6 & 24,77 & 148,64 & 26,26 & 157,56 & 27,84 & 167,01 \\
\hline & $\begin{array}{l}\text { Aplicação } \\
\text { isca } \\
\text { herbicida }\end{array}$ & d homem-1 & 1 & 95,28 & 95,28 & 101,00 & 101,00 & 107,06 & 107,06 \\
\hline & $\begin{array}{l}\text { aplicação } \\
\text { c/costal }\end{array}$ & d homem-1 & 2 & 95,28 & 190,56 & 101,00 & 202,00 & 107,06 & 214,12 \\
\hline \multirow{3}{*}{$\begin{array}{l}\text { Controle de plantas } \\
\text { daninhas }\end{array}$} & produto & aplicação & 2 & 92,90 & 185,80 & 98,47 & 196,95 & 104,38 & 208,76 \\
\hline & $\begin{array}{l}\text { roçaderia } \\
\text { manual }(8 x)\end{array}$ & $R \$ d^{-1}$ & 8 & 347,42 & 2779,35 & 368,26 & 2946,12 & 390,36 & 3122,88 \\
\hline & $\begin{array}{l}\text { roçadeira } \\
\text { trator }(8 x)\end{array}$ & $\mathrm{R} \$ \mathrm{~h}^{-1}$ & 22,64 & 22,27 & 504,24 & 23,61 & 534,49 & 25,02 & 566,56 \\
\hline Transporte interno colheita & & $R \$ d^{-1}$ & 20 & 22,27 & 445,44 & 23,61 & 472,17 & 25,02 & 500,50 \\
\hline Mão de obra colheita & & $\mathrm{d}_{\text {homem-1 }}^{-1}$ & 20 & 95,28 & 1905,63 & 101,00 & 2019,96 & 107,06 & 2141,16 \\
\hline TOTAL & & $\mathrm{R} \$$ & & & $40.011,34$ & & $42.260,33$ & & $45.439,90$ \\
\hline
\end{tabular}


Tabela 6. Descrição dos itens para manutenção de três hectares de uva Niágara Rosada nos anos de cultivo 6, 7 e 8

(continua)

\begin{tabular}{|c|c|c|c|c|c|c|c|c|}
\hline \multirow[b]{2}{*}{ Descrição } & \multirow[b]{2}{*}{ Unidade } & \multirow[b]{2}{*}{ Quantidade } & \multicolumn{2}{|c|}{ Ano 6} & \multicolumn{2}{|c|}{ Ano 7} & \multicolumn{2}{|c|}{ Ano 8} \\
\hline & & & $\begin{array}{c}\text { Valor } \\
\text { unitário }\end{array}$ & $\begin{array}{l}\text { Valor } \\
\text { total }\end{array}$ & $\begin{array}{c}\text { Valor } \\
\text { unitário }\end{array}$ & $\begin{array}{l}\text { Valor } \\
\text { total }\end{array}$ & $\begin{array}{c}\text { Valor } \\
\text { unitário }\end{array}$ & $\begin{array}{l}\text { Valor } \\
\text { total }\end{array}$ \\
\hline & & & ----------- & & $\square \pi$ & 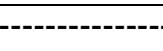 & ---------- & --------- \\
\hline \multicolumn{9}{|l|}{ Adubação de produção } \\
\hline sulfato de amônio & $\mathrm{t}$ & 1,5 & 1276,67 & 1915,00 & 1353,27 & 2029,90 & 1434,46 & 2151,69 \\
\hline superfosfato triplo & $\mathrm{t}$ & 0,645 & 2411,48 & 1555,41 & 2556,17 & 1648,73 & 2709,54 & 1747,65 \\
\hline cloreto de potássio & $\mathrm{t}$ & 0,39 & 1773,15 & 691,53 & 1879,54 & 733,02 & 1992,31 & 777,00 \\
\hline Esterco de galinha poedeira & $\mathrm{t}$ & 7,5 & 170,22 & 1276,67 & 180,44 & 1353,27 & 191,26 & 1434,46 \\
\hline Ãcido bórico & $\mathrm{kg}$ & 30 & 5,36 & 160,80 & - & - & - & - \\
\hline \multicolumn{9}{|l|}{ Irrigação } \\
\hline $\begin{array}{l}\text { Tubo gotejador } 16 \mathrm{~mm} \\
\text { autocompesante }\end{array}$ & $\mathrm{m}$ & 15648 & - & - & 1,42 & 22220,16 & - & - \\
\hline mão de obra instalação & - & - & - & - & 4500,00 & 4500,00 & - & - \\
\hline custo de manutenção & anual & 1 & 1739,69 & 1739,69 & 1844,07 & 1844,07 & 1954,72 & 1954,72 \\
\hline energia elétrica & $\mathrm{kW} \mathrm{h}^{-1}$ & 1361,6 & 0,47 & 636,22 & 0,50 & 674,39 & 0,53 & 714,86 \\
\hline \multicolumn{9}{|l|}{ Materiais } \\
\hline tesoura de poda & 1 & 6 & - & - & 42,55 & 255,29 & - & - \\
\hline tesoura de colheita & 1 & 6 & - & - & 36,88 & 221,26 & - & - \\
\hline alceador & 1 & 3 & - & - & 268,10 & 804,29 & - & - \\
\hline fita para alceador $11 \mathrm{~mm} \times 30 \mathrm{~m}$ & pct $\mathrm{c} / 10$ & 120 & 9,93 & 1191,56 & 10,53 & 1263,05 & 11,16 & 1338,83 \\
\hline grampo para alceador $6 / 4 b$ & pct c/4800 & 75 & 3,97 & 297,89 & 4,21 & 315,76 & 4,46 & 334,71 \\
\hline Caixas plásticas colheita & 1 & 30 & 22,75 & 682,59 & 24,12 & 723,54 & 25,57 & 766,95 \\
\hline \multicolumn{9}{|l|}{ Operações } \\
\hline Adubação de produção manual & d homem-1 & 12 & 113,48 & 1361,78 & 120,29 & 1443,49 & 127,51 & 1530,09 \\
\hline
\end{tabular}


Tabela 6. Descrição dos itens para manutenção de três hectares de uva Niágara Rosada nos anos de cultivo 6, 7 e 8

(conclusão)

\begin{tabular}{|c|c|c|c|c|c|c|c|c|c|}
\hline \multirow[b]{2}{*}{ Descrição } & & \multirow[b]{2}{*}{ Unidade } & \multirow[b]{2}{*}{ Quantidade } & \multicolumn{2}{|c|}{ Ano 6} & \multicolumn{2}{|c|}{ Ano 7} & \multicolumn{2}{|c|}{ Ano 8} \\
\hline & & & & $\begin{array}{c}\text { Valor } \\
\text { unitário }\end{array}$ & $\begin{array}{l}\text { Valor } \\
\text { total }\end{array}$ & $\begin{array}{c}\text { Valor } \\
\text { unitário }\end{array}$ & $\begin{array}{l}\text { Valor } \\
\text { total }\end{array}$ & $\begin{array}{c}\text { Valor } \\
\text { unitário }\end{array}$ & $\begin{array}{l}\text { Valor } \\
\text { total }\end{array}$ \\
\hline \multirow[b]{2}{*}{ Adubação de produção } & \multirow[b]{2}{*}{ trator } & \multirow[b]{2}{*}{$R \$ d^{-1}$} & \multirow[b]{2}{*}{3} & \multicolumn{6}{|c|}{ - } \\
\hline & & & & 212,21 & 636,64 & 224,94 & 674,83 & 238,44 & 715,32 \\
\hline \multirow[t]{2}{*}{ Aplicação cianamida } & trator & $\mathrm{R} \$ \mathrm{~h}^{-1}$ & 3,41 & 26,53 & 90,45 & 28,12 & 95,88 & 29,80 & 101,63 \\
\hline & produto & $\mathrm{L}$ & 18 & 157,46 & 2834,20 & 166,90 & 3004,25 & 176,92 & 3184,51 \\
\hline $\begin{array}{l}\text { Tutoramento de } \\
\text { plantas }\end{array}$ & manual & $\mathrm{d}_{\text {homem }}{ }^{-1}$ & 200 & 113,48 & 22696,31 & 120,29 & 24058,08 & 127,51 & 25501,57 \\
\hline \multirow[t]{4}{*}{ Controle de doenças } & trator & $\mathrm{R} \$ \mathrm{~h}^{-1}$ & 54,56 & 26,53 & 1447,28 & 28,12 & 1534,11 & 29,80 & 1626,16 \\
\hline & produto & aplicação & 16 & 94,32 & 1509,08 & 99,98 & 1599,62 & 105,97 & 1695,60 \\
\hline & trator & $\mathrm{R} \$ \mathrm{~h}^{-1}$ & 3,41 & 26,53 & 90,45 & 28,12 & 95,88 & 29,80 & 101,63 \\
\hline & produto & aplicação & 1 & 63,83 & 63,83 & 67,66 & 67,66 & 71,72 & 71,72 \\
\hline \multirow[t]{3}{*}{ Controle de pragas } & $\begin{array}{l}\text { Fipronil - } \\
\text { Isca formiga }\end{array}$ & $\mathrm{kg}$ & 6 & 29,51 & 177,03 & 31,28 & 187,65 & 33,15 & 198,91 \\
\hline & & d homem-1 & 1 & 113,48 & 113,48 & 120,29 & 120,29 & 127,51 & 127,51 \\
\hline & $\begin{array}{l}\text { aplicação } \\
\text { c/costal }\end{array}$ & d homem-1 & 2 & 113,48 & 226,96 & 120,29 & 240,58 & 127,51 & 255,02 \\
\hline \multirow{3}{*}{$\begin{array}{l}\text { Controle de plantas } \\
\text { daninhas }\end{array}$} & produto & aplicação & 2 & 110,64 & 221,29 & 117,28 & 234,57 & 124,32 & 248,64 \\
\hline & $\begin{array}{l}\text { roçaderia } \\
\text { manual }(8 x)\end{array}$ & $R \$ d^{-1}$ & 8 & 413,78 & 3310,26 & 438,61 & 3508,87 & 464,93 & 3719,40 \\
\hline & $\begin{array}{l}\text { roçadeira } \\
\text { trator }(8 x)\end{array}$ & $\mathrm{R} \$ \mathrm{~h}^{-1}$ & 22,64 & 26,53 & 600,56 & 28,12 & 636,59 & 29,80 & 674,78 \\
\hline \multicolumn{2}{|c|}{ Transporte interno colheita } & $R \$ d^{-1}$ & 20 & 26,53 & 530,53 & 28,12 & 562,36 & 29,80 & 596,10 \\
\hline \multicolumn{2}{|l|}{ Mão de obra colheita } & $\mathrm{d}_{\text {homem }}^{-1}$ & 20 & 113,48 & 2269,63 & 120,29 & 2405,81 & 127,51 & 2550,16 \\
\hline \multicolumn{2}{|l|}{ TOTAL } & $\mathrm{R} \$$ & & & $48.327,09$ & & $79.057,27$ & & $54.119,65$ \\
\hline
\end{tabular}


Tabela 7. Descrição dos itens para manutenção de três hectares de uva Niágara Rosada nos anos de cultivo 9, 10 e 11

(continua)

\begin{tabular}{|c|c|c|c|c|c|c|c|c|c|}
\hline & & & & & & & & & 11 \\
\hline Descrição & & Unidade & Quantidade & $\begin{array}{c}\text { Valor } \\
\text { unitário }\end{array}$ & $\begin{array}{l}\text { Valor } \\
\text { total }\end{array}$ & $\begin{array}{c}\text { Valor } \\
\text { unitário }\end{array}$ & $\begin{array}{l}\text { Valor } \\
\text { total }\end{array}$ & $\begin{array}{c}\text { Valor } \\
\text { unitário }\end{array}$ & $\begin{array}{l}\text { Valor } \\
\text { total }\end{array}$ \\
\hline & & & & . & 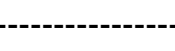 & $-\mathrm{R} \$$ & $-----\cdot$ & - & -------- \\
\hline Adubação de produção & & & & & & & & & \\
\hline sulfato de amônio & & $\mathrm{t}$ & 1,5 & 1520,53 & 2280,80 & 1611,76 & 2417,64 & 1708,47 & 2562,70 \\
\hline superfosfato triplo & & $\mathrm{t}$ & 0,645 & 2872,11 & 1852,51 & 3044,44 & 1963,66 & 3227,11 & 2081,48 \\
\hline cloreto de potássio & & $\mathrm{t}$ & 0,39 & 2111,85 & 823,62 & 2238,56 & 873,04 & 2372,87 & 925,42 \\
\hline Esterco de galinha poede & & $\mathrm{t}$ & 7,5 & 202,74 & 1520,53 & 214,90 & 1611,76 & 227,80 & 1708,47 \\
\hline Ãcido bórico & & $\mathrm{kg}$ & 30 & - & - & - & - & - & - \\
\hline Irrigação & & & & & & & & & \\
\hline custo de manutenção & & anual & 1 & 2072,00 & 2072,00 & 2196,32 & 2196,32 & 2328,10 & 2328,10 \\
\hline energia elétrica & & $\mathrm{kW} \mathrm{h} \mathrm{h}^{-1}$ & 1361,6 & 0,56 & 757,75 & 0,59 & 803,21 & 0,63 & 851,41 \\
\hline Materiais & & & & & & & & & \\
\hline fita para alceador $11 \mathrm{~mm}$ & $30 \mathrm{~m}$ & pct c/10 & 120 & 11,83 & 1419,16 & 12,54 & 1504,31 & 13,29 & 1594,57 \\
\hline grampo para alceador $6 / 4$ & & pct c/4800 & 75 & 4,73 & 354,79 & 5,01 & 376,08 & 5,32 & 398,64 \\
\hline Caixas plásticas colheita & & 1 & 30 & 27,10 & 812,97 & 28,73 & 861,75 & 30,45 & 913,46 \\
\hline Operações & & & & & & & & & \\
\hline Adubação de produção & manual & d homem-1 & 12 & 135,16 & 1621,90 & 143,27 & 1719,21 & 151,86 & 1822,37 \\
\hline & trator & $R \$ d^{-1}$ & 3 & 252,75 & 758,24 & 267,91 & 803,73 & 283,99 & 851,96 \\
\hline Aplicação dormex & trator & $\mathrm{R} \$ \mathrm{~h}^{-1}$ & 3,41 & 31,59 & 107,73 & 33,49 & 114,20 & 35,50 & 121,05 \\
\hline & produto & $L$ & 18 & 187,53 & 3375,58 & 198,78 & 3578,11 & 210,71 & 3792,80 \\
\hline Tutoramento de plantas & manual & d homem-1 & 200 & 135,16 & 27031,66 & 143,27 & 28653,56 & 151,86 & 30372,78 \\
\hline Controle de doenças & trator & $R \$ h^{-1}$ & 54,56 & 31,59 & 1723,73 & 33,49 & 1827,15 & 35,50 & 1936,78 \\
\hline
\end{tabular}


Tabela 7. Descrição dos itens para manutenção de três hectares de uva Niágara Rosada nos anos de cultivo 9, 10 e 11

(conclusão)

\begin{tabular}{|c|c|c|c|c|c|c|c|c|c|}
\hline \multirow[b]{2}{*}{ Descrição } & & \multirow[b]{2}{*}{ Unidade } & \multirow[b]{2}{*}{ Quantidade } & \multicolumn{2}{|c|}{ Ano 9} & \multicolumn{2}{|c|}{ Ano 10} & \multicolumn{2}{|c|}{ Ano 11} \\
\hline & & & & $\begin{array}{c}\text { Valor } \\
\text { unitário }\end{array}$ & $\begin{array}{l}\text { Valor } \\
\text { total }\end{array}$ & $\begin{array}{c}\text { Valor } \\
\text { unitário }\end{array}$ & $\begin{array}{l}\text { Valor } \\
\text { total }\end{array}$ & $\begin{array}{c}\text { Valor } \\
\text { unitário }\end{array}$ & $\begin{array}{l}\text { Valor } \\
\text { total }\end{array}$ \\
\hline & & & & - & - & ----- $R \Phi$ & ---- & ---- & ------- \\
\hline \multirow{3}{*}{ Controle de doenças } & produto & aplicação & 16 & 112,33 & 1797,34 & 119,07 & 1905,18 & 126,22 & 2019,49 \\
\hline & trator & $\mathrm{R} \$ \mathrm{~h}^{-1}$ & 3,41 & 31,59 & 107,73 & 33,49 & 114,20 & 35,50 & 121,05 \\
\hline & produto & aplicação & 1 & 76,03 & 76,03 & 80,59 & 80,59 & 85,42 & 85,42 \\
\hline \multirow[t]{3}{*}{ Controle de pragas } & $\begin{array}{l}\text { Fipronil - } \\
\text { Isca } \\
\text { formiga }\end{array}$ & $\mathrm{kg}$ & 6 & 35,14 & 210,85 & 37,25 & 223,50 & 39,48 & 236,91 \\
\hline & $\begin{array}{l}\text { Aplicação } \\
\text { isca } \\
\text { herbicida }\end{array}$ & d homem-1 & 1 & 135,16 & 135,16 & 143,27 & 143,27 & 151,86 & 151,86 \\
\hline & $\begin{array}{l}\text { aplicação } \\
\text { c/costal }\end{array}$ & $\mathrm{d}_{\text {homem}}-1$ & 2 & 135,16 & 270,32 & 143,27 & 286,54 & 151,86 & 303,73 \\
\hline \multirow{3}{*}{$\begin{array}{l}\text { Controle } \\
\text { daninhas }\end{array}$} & produto & aplicação & 2 & 131,78 & 263,56 & 139,69 & 279,37 & 148,07 & 296,13 \\
\hline & $\begin{array}{l}\text { manual } \\
(8 x)\end{array}$ & $R \$ d^{-1}$ & 8 & 492,82 & 3942,57 & 522,39 & 4179,12 & 553,73 & 4429,87 \\
\hline & $\begin{array}{l}\text { roçadeira } \\
\text { trator }(8 x)\end{array}$ & $\mathrm{R} \$ \mathrm{~h}^{-1}$ & 22,64 & 31,59 & 715,27 & 33,49 & 758,19 & 35,50 & 803,68 \\
\hline \multicolumn{2}{|l|}{ Transporte interno colheita } & $R \$ d^{-1}$ & 20 & 31,59 & 631,87 & 33,49 & 669,78 & 35,50 & 709,96 \\
\hline \multicolumn{2}{|l|}{ Mão de obra colheita } & $\mathrm{d}_{\text {homem }}^{-1}$ & 20 & 135,16 & 2703,17 & 143,27 & 2865,36 & 151,86 & 3037,28 \\
\hline \multicolumn{2}{|l|}{ TOTAL } & $\mathrm{R} \$$ & & & $57.366,83$ & & $60.808,84$ & & $64.457,37$ \\
\hline
\end{tabular}


Tabela 8. Descrição dos itens para manutenção de três hectares de uva Niágara Rosada nos anos de cultivo 12 e 13

(continua)

\begin{tabular}{|c|c|c|c|c|c|c|c|}
\hline & & & & \multicolumn{2}{|c|}{ Ano 12} & \multicolumn{2}{|c|}{ Ano 13} \\
\hline \multicolumn{2}{|c|}{ Descrição } & Unidade & Quantidade & Valor unitário & $\begin{array}{l}\text { Valor } \\
\text { total }\end{array}$ & $\begin{array}{c}\text { Valor } \\
\text { unitário }\end{array}$ & $\begin{array}{l}\text { Valor } \\
\text { total }\end{array}$ \\
\hline & & & & ------------- & $----\cdot-$ & --------- & ------------ \\
\hline \multicolumn{8}{|l|}{ Adubação de produção } \\
\hline sulfato de amônio & & $\mathrm{t}$ & 1,5 & 1810,98 & 2716,47 & 1919,64 & 2879,45 \\
\hline superfosfato triplo & & $\mathrm{t}$ & 0,645 & 3420,73 & 2206,37 & 3625,98 & 2338,76 \\
\hline cloreto de potássio & & $\mathrm{t}$ & 0,39 & 2515,25 & 980,95 & 2666,16 & 1039,80 \\
\hline Esterco de galinha poed & & $\mathrm{t}$ & 7,5 & 241,46 & 1810,98 & 255,95 & 1919,64 \\
\hline \multicolumn{8}{|l|}{ Irrigação } \\
\hline custo de manutenção & & anual & 1 & 2467,79 & 2467,79 & 2615,86 & 2615,86 \\
\hline energia elétrica & & $\mathrm{kW} \mathrm{h} \mathrm{h}^{-1}$ & 1361,6 & 0,66 & 902,49 & 0,70 & 956,64 \\
\hline \multicolumn{8}{|l|}{ Materiais } \\
\hline fita para alceador $11 \mathrm{~mm}$ & & pct $\mathrm{c} / 10$ & 120 & 14,09 & 1690,25 & 14,93 & 1791,66 \\
\hline grampo para alceador $6 /$ & & pct c/4800 & 75 & 5,63 & 422,56 & 5,97 & 447,91 \\
\hline \multicolumn{8}{|l|}{ Operações } \\
\hline \multirow[t]{2}{*}{ Adubação de produção } & manual & d homem-1 & 12 & 160,98 & 1931,71 & 170,63 & 2047,61 \\
\hline & trator & $R \$ d^{-1}$ & 3 & 301,02 & 903,07 & 319,09 & 957,26 \\
\hline \multirow[t]{2}{*}{ Aplicação dormex } & trator & $R \$ h^{-1}$ & 3,41 & 37,63 & 128,31 & 39,89 & 136,01 \\
\hline & produto & $L$ & 18 & 223,35 & 4020,37 & 236,76 & 4261,59 \\
\hline Tutoramento de plantas & manual & d homem-1 & 200 & 160,98 & 32195,14 & 170,63 & 34126,85 \\
\hline \multirow[t]{2}{*}{ Controle de doenças } & trator & $R \$ h^{-1}$ & 54,56 & 37,63 & 2052,99 & 39,89 & 2176,17 \\
\hline & produto & aplicação & 16 & 133,79 & 2140,66 & 141,82 & 2269,09 \\
\hline
\end{tabular}


Tabela 8. Descrição dos itens para manutenção de três hectares de uva Niágara Rosada nos anos de cultivo 12 e 13

(conclusão)

\begin{tabular}{|c|c|c|c|c|c|c|c|}
\hline \multirow[b]{2}{*}{ Descrição } & & \multirow[b]{2}{*}{ Unidade } & \multirow[b]{2}{*}{ Quantidade } & \multicolumn{2}{|c|}{ Ano 12} & \multicolumn{2}{|c|}{ Ano 13} \\
\hline & & & & Valor unitário & $\begin{array}{l}\text { Valor } \\
\text { total }\end{array}$ & $\begin{array}{c}\text { Valor } \\
\text { unitário }\end{array}$ & $\begin{array}{l}\text { Valor } \\
\text { total }\end{array}$ \\
\hline & & & & --- & ------- & ---------. & ------ \\
\hline \multirow{4}{*}{ Controle de pragas } & trator & $\mathrm{R} \$ \mathrm{~h}^{-1}$ & 3,41 & 37,63 & 128,31 & 39,89 & 136,01 \\
\hline & produto & aplicação & 1 & 90,55 & 90,55 & 95,98 & 95,98 \\
\hline & Fipronil -Isca formiga & $\mathrm{kg}$ & 6 & 41,85 & 251,12 & 44,36 & 266,19 \\
\hline & Aplicação isca & $\mathrm{d}_{\text {homem }}^{-1}$ & 1 & 160,98 & 160,98 & 170,63 & 170,63 \\
\hline \multirow{4}{*}{ Controle de plantas daninhas } & herbicida aplicação c/costal & d homem-1 & 2 & 160,98 & 321,95 & 170,63 & 341,27 \\
\hline & produto & aplicação & 2 & 156,95 & 313,90 & 166,37 & 332,74 \\
\hline & roçaderia manual $(8 x)$ & $R \$ d^{-1}$ & 8 & 586,96 & 4695,66 & 622,18 & 4977,40 \\
\hline & roçadeira trator $(8 x)$ & $\mathrm{R} \$ \mathrm{~h}^{-1}$ & 22,64 & 37,63 & 851,90 & 39,89 & 903,01 \\
\hline Transporte interno colheita & & $R \$ d^{-1}$ & 20 & 37,63 & 752,56 & 39,89 & 797,72 \\
\hline Mão de obra colheita & & $\mathrm{d}_{\text {homem}}^{-1}$ & 20 & 160,98 & 3219,51 & 170,63 & 3412,69 \\
\hline TOTAL & & $\mathrm{R} \$$ & & & $67.356,55$ & & $71.397,94$ \\
\hline
\end{tabular}


O fluxo de caixa do projeto foi construído para 13 anos de atividade (Tabela 9). O custo inicial do investimento no primeiro ano foi de $R \$ 330.390,00$. Neste valor, foram incluídas todas as despesas para instalação do vinhedo, a parcela de juros do financiamento e o custo de oportunidade da terra. No ano 2, o custo total anual foi de $R \$ 202.277,50$. Considerando-se os valores para o cultivo de 1 ha, o custo de implantação no primeiro ano foi de $R \$ 110.130,00$, e o custo de produção no segundo ano de $\mathrm{R} \$ 67.425,83$. A partir do ano 3 , as despesas apresentaram valores que variaram de $\mathrm{R} \$ 92.670,9$ a $\mathrm{R} \$ 123.809,4$ para o custeio de 3 ha cultivados. Assim, para cada 1 ha, os valores foram de $R \$ 30.890,30$ a $R \$ 41.269,80$. O custo de produção médio, resultante do somatório das despesas anuais dividido pelo período de atividade (13 anos), foi de $R \$ 128.166,45$ para 3 ha ou de $R \$ 42.722,15$ por ha.

Cappello 4 verificou o custo de produção em propriedades situadas no Escritório de Desenvolvimento Rural [EDR] de Campinas, EDR mais próximo do município de Piracicaba e importante região produtora de uvas de mesa. De acordo com o autor, o custo de produção por ha na safra principal no ano de 2012/13 foi de $R \$ 25.916,90$. Segundo o mesmo autor, o custo de produção para a safra principal somada a temporã, foi de $38.811,05 \mathrm{R} \$$ ha $^{-1}$, valor mais próximo do obtido no presente estudo. Bendlin e Souza (2013) obtiveram o custo de implantação no valor de $R \$ 56.408,66$ para a variedade Niágara Rosada cultivada no sistema em manjedoura. Os mesmos autores estimaram os custos do segundo ao quinto ano de produção e obtiveram o valor de 12.398,09 $\mathrm{R} \$ \mathrm{ha}^{-1}$, valores inferiores aos verificados neste trabalho. Reis e Reis (2016) verificaram o valor de $R \$ 68.300,00$ para a implantação de um ha de uva irrigada em Petrolina-PE. No segundo ano, o custo total foi estimado em $\mathrm{R} \$ 34.108,00$ $\mathrm{ha}^{-1}$, e do terceiro ao vigésimo ano os valores foram fixados em $\mathrm{R} \$ 41.194,00 \mathrm{ha}^{-1}$. Embora os valores estimados por esses autores para os dois primeiros anos de projeto sejam inferiores aos observados no presente trabalho, os valores do terceiro ano em diante são similares.

O VPL obtido no presente estudo foi $R \$ 398.951,36$, ou seja, agregou-se a quantia de $\mathrm{R} \$ 398.951,36$ em relação a melhor aplicação do dinheiro. No caso, um investimento a uma taxa de juros de $11,45 \%$ (Tabela 10). A TIR obtida foi de 27,34\%, superior à taxa mínima de atratividade [TMA] estipulada para o projeto $(11,45 \%)$ (Tabela 10). Assim, obteve-se TMA inferior à TIR e VPL maior que zero, indicando tomada de decisão favorável à realização do empreendimento. De acordo com esses

\footnotetext{
${ }^{4}$ Cf. nota 1.
} 
dois indicadores, o projeto saldou o investimento inicial e garantiu a remuneração mínima exigida pelo investidor.

O tempo de payback serve como um indicador do risco do projeto. Caso o payback de um investimento seja superior ao tempo máximo estabelecido pela empresa para recuperar o investimento inicial, o mesmo não deve ser aceito. 0 payback simples não considera o custo de capital no tempo. Em contrapartida, o payback descontado considera o custo do capital no tempo. No projeto em questão, obteve-se payback simples de 5 anos, 1 mês e 18 dias e payback descontado de 6 anos, 3 meses e 5 dias (Tabela 10). Assim, para ambos os indicadores de payback, o tempo de retorno do capital inicial investido foi inferior ao período do projeto, estabelecido em 13 anos, indicando um baixo risco de investimento com um retorno a médio prazo do capital investido.

A relação benefício-custo foi positiva, no valor de 1,81 , ou seja, as receitas corresponderam a 1,81 vez o valor dos custos. Portanto, o valor das receitas, descontadas da taxa de desconto $(11,45 \%)$, são maiores que as despesas do projeto (Tabela 10).

Reis e Reis (2016) em um estudo de viabilidade econômica da produção de uva irrigada em Petrolina, PE, obtiveram VPL de $R \$ 267.544,34$, TIR de 51,9\%, payback de 3,3 anos e relação custo-benefício de 1,65 . Cappello ${ }^{5}$ verificou VPL de $R \$$ 125.538,77 e TIR de 28,0\% para o cultivo de Niágara Rosada na região da EDR de Campinas, SP. Kreuz et al. (2005) avaliaram o cultivo de uva no meio oeste catarinense em diferentes sistemas de condução, e obteve valores de VPL de até R\$ 153.110,00, valores de TIR de 22,62\% a 52,65\%, e períodos de payback de 3 a 7 anos. Em outro estudo, a relação benefício-custo para o cultivo de Niágara Rosada no sistema em latada foi estimada em 2,09 (Embrapa, 2003). Para o cultivo de uvas de mesa na região do Vale do São Francisco, verificou-se a relação custo-benefício de 1,33 (Embrapa, 2010). Em todos os trabalhos mencionados, assim como no presente estudo, os valores dos índices de rentabilidade estimados para o cultivo de uvas de mesa foram positivos, evidenciando a viabilidade econômica desta atividade.

\footnotetext{
${ }^{5}$ Cf. nota 1
} 
Tabela 9. Fluxo de caixa (em mil reais) para o cultivo de três hectares de uva Niágara Rosada em Piracicaba, SP

(continua)

\begin{tabular}{|c|c|c|c|c|c|c|c|c|c|c|c|c|c|}
\hline & Ano 1 & Ano 2 & Ano 3 & Ano 4 & Ano 5 & Ano 6 & Ano 7 & Ano 8 & Ano 9 & Ano 10 & Ano 11 & Ano 12 & Ano 13 \\
\hline \multicolumn{14}{|c|}{ Implantação e manutenção do vinhedo } \\
\hline Mudas & 67,50 & 0,0 & 0,0 & 0,0 & 0,0 & 0,0 & 0,0 & 0,0 & 0,0 & 0,0 & 0,0 & 0,0 & 0,0 \\
\hline $\begin{array}{l}\text { Adubação e correção } \\
\text { do solo }\end{array}$ & 7,23 & 3,47 & 4,71 & 4,84 & 5,13 & 5,60 & 5,77 & 6,11 & 6,48 & 6,87 & 7,28 & 7,71 & 8,18 \\
\hline Irrigação & 27,82 & 1,88 & 1,99 & 2,12 & 2,24 & 2,38 & 29,24 & 2,67 & 2,83 & 2,99 & 3,18 & 3,37 & 3,58 \\
\hline $\begin{array}{l}\text { Instalacão do } \\
\text { sistema de condução }\end{array}$ & 53,66 & 0,0 & 0,0 & 0,0 & 0,0 & 0,0 & 0,0 & 0,0 & 0,0 & 0,0 & 0,0 & 0,0 & 0,0 \\
\hline Maquinário & 100,09 & 0,0 & 0,0 & 0,0 & 0,0 & 0,0 & 0,0 & 0,0 & 0,0 & 0,0 & 0,0 & 0,0 & 0,0 \\
\hline $\begin{array}{l}\text { Depreciação } \\
\text { maquinário }\end{array}$ & 0,0 & 7,49 & 7,49 & 7,49 & 7,49 & 7,49 & 7,49 & 7,49 & 7,49 & 7,49 & 7,49 & 7,49 & 7,49 \\
\hline $\begin{array}{l}\text { Manutenção } \\
\text { maquinário }\end{array}$ & 0,0 & 0,45 & 0,79 & 1,12 & 1,46 & 1,80 & 2,14 & 2,47 & 2,81 & 3,15 & 3,48 & 3,82 & 4,16 \\
\hline Materiais & 2,54 & 108,06 & 1,25 & 1,33 & 2,05 & 2,17 & 3,58 & 2,44 & 2,59 & 2,74 & 2,91 & 2,11 & 2,24 \\
\hline Operações & 24,58 & 30,24 & 32,06 & 33,98 & 36,02 & 38,18 & 40,47 & 42,90 & 45,47 & 48,20 & 51,09 & 54,16 & 57,41 \\
\hline Total & 283,42 & 151,59 & 48,29 & 50,88 & 54,39 & 57,62 & 88,68 & 64,08 & 67,67 & 71,45 & 75,43 & 78,67 & 83,05 \\
\hline \multicolumn{14}{|l|}{ Financiamento } \\
\hline Juros Financiamento & 34,97 & 34,97 & 34,97 & 33,22 & 26,24 & 19,23 & 12,24 & 5,25 & & & & & \\
\hline $\begin{array}{l}\text { Amortização } \\
\text { Financiamento }\end{array}$ & 0,0 & 0,0 & 0,0 & 84,00 & 84,00 & 84,00 & 84,00 & 84,00 & & & & & \\
\hline Parcela Finciamento & 34,97 & 34,97 & 34,97 & 117,22 & 110,24 & 103,23 & 96,24 & 89,25 & & & & & \\
\hline $\begin{array}{l}\text { Saldo final } \\
\text { financiamento }\end{array}$ & 420,00 & 420,00 & 420,00 & 336,00 & 252,00 & 168,00 & 84,00 & 0,0 & & & & & \\
\hline Funrural & - & 2,99 & 3,74 & 4,49 & 5,86 & 5,86 & 5,86 & 6,04 & 5,88 & 5,71 & 5,84 & 5,66 & 5,31 \\
\hline $\begin{array}{l}\text { Custo de } \\
\text { oportunidade da terra }\end{array}$ & 12,00 & 12,72 & 13,48 & 14,29 & 15,15 & 16,06 & 17,02 & 18,04 & 1,91 & 20,27 & 21,49 & 22,78 & 24,15 \\
\hline Total despesas ${ }^{\star 1}$ & 330,39 & 202,28 & 100,49 & 102,88 & 101,64 & 98,77 & 123,81 & 93,42 & 92,67 & 97,43 & 102,77 & 107,11 & 112,51 \\
\hline $\begin{array}{l}\text { Valor residual } \\
\text { maquinário }\end{array}$ & 0,0 & 0,0 & 0,0 & 0,0 & 0,0 & 0,0 & 0,0 & 0,0 & 0,0 & 0,0 & 0,0 & 0,0 & 9,99 \\
\hline
\end{tabular}


Tabela 9. Fluxo de caixa (em mil reais) para o cultivo de três hectares de uva Niágara Rosada em Piracicaba, SP

(conclusão)

\begin{tabular}{|c|c|c|c|c|c|c|c|c|c|c|c|c|c|}
\hline & Ano 1 & Ano 2 & Ano 3 & Ano 4 & Ano 5 & Ano 6 & Ano 7 & Ano 8 & Ano 9 & Ano 10 & Ano 11 & Ano 12 & Ano 13 \\
\hline Receita bruta*2 & 0,0 & 142,50 & 178,13 & 213,75 & 279,17 & 279,17 & 279,17 & 287,82 & 279,83 & 271,83 & 278,19 & 269,76 & 262,89 \\
\hline Fluxo de caixa nominal & $-330,39$ & $-59,78$ & 77,64 & 110,87 & 177,52 & 180,39 & 155,36 & 194,40 & 187,15 & 174,40 & 175,42 & 162,65 & 150,38 \\
\hline $\begin{array}{l}\text { Fluxo de caixa } \\
\text { acumulado }\end{array}$ & $-330,39$ & $-390,17$ & $-312,53$ & $-201,66$ & $-24,14$ & 156,25 & 311,61 & 506,01 & 693,17 & 867,57 & 1042,99 & 1205,64 & 135,60 \\
\hline $\begin{array}{l}\text { Fluxo de caixa } \\
\text { descontado }\end{array}$ & $-300,35$ & $-49,40$ & 58,33 & 75,73 & 110,23 & 101,83 & 79,72 & 90,69 & 7,94 & 67,24 & 61,49 & 51,82 & 43,56 \\
\hline $\begin{array}{l}\text { Fluxo de caixa } \\
\text { descontado }\end{array}$ & $-300,35$ & $-349,76$ & $-291,43$ & $-215,70$ & $-105,48$ & $-3,65$ & 76,07 & 166,76 & 246,14 & 313,37 & 374,86 & 426,68 & 470,24 \\
\hline
\end{tabular}

*1 Total das despesas corresponde ao somatório dos custos com a implantação e manutenção do vinhedo, juros do financiamento, Funrural e custo de oportunidade da terra

*2 Receita bruta da produção somada ao valor residual do maquinário e implementos

Fonte: Resultados originais da pesquisa 
Tabela 10. Indicadores econômicos Valor Presente Líquido [VPL], Taxa Interna de Retorno [TIR], payback simples, payback descontado e relação benefício-custo para o cultivo de três hectares de uva Niágara Rosada em Piracicaba, SP

\begin{tabular}{ll}
\hline VPL & $\mathrm{R} \$ 398.951,36$ \\
TIR & $27,34 \%$ \\
Payback simples & 5 anos, 1 mês e 18 dias \\
Payback descontado & 6 anos, 3 meses e 5 dias \\
Relação benefício-custo & 1,81 \\
\hline
\end{tabular}

Fonte: Resultados originais da pesquisa

Embora o investimento inicial para a implantação da cultura da videira seja alto, o presente estudo revelou ser esta uma atividade economicamente rentável. No projeto, considerou-se um fluxo de caixa de 13 anos de atividade e a colheita de uma única safra anual. Entretanto, o período de produção da videira pode ser muito maior que o considerado, além de haver a possibilidade da realização da safra principal seguida da safra temporã, gerando duas produções anuais. Duas safras anuais representam um maior potencial de produção, além de períodos de colheita em épocas distintas, o que pode ser uma boa estratégia para a obtenção de melhores preços de comercialização da fruta. Embora não tenha sido considerado no estudo, a produção de uma segunda safra, aliada a uma vida útil mais longa do vinhedo, evidenciam um potencial de rentabilidade ao produtor rural ainda maior ao verificado no projeto proposto.

\section{Conclusão}

O estudo apresenta VPL positivo e TIR superior à taxa mínima de atratividade, fixada em $11,45 \%$. Portanto, o projeto é capaz de pagar o investimento inicial e garantir a remuneração mínima exigida pelo investidor. De acordo com os valores de payback simples e payback descontado, verifica-se que o tempo de retorno do capital inicial investido é inferior ao período do projeto, indicando um baixo risco do investimento. A relação benefício-custo é positiva e favorável a aceitação do projeto. De acordo com os indicadores financeiros VPL, TIR, payback simples, payback descontado e relação benefício-custo, o cultivo de uva Niágara Rosada é economicamente viável.

\section{Referências}

Assaf Neto, A.; Lima, F.G. 2011. Curso de administração financeira. 2ed. Atlas, São Paulo, São Paulo, Brasil. 
Associação Brasileira de Tecnologia para Construção e Mineração [SOBRATEMA]. 2016. Tabela custo-horário. Disponível em:

<https://www.sobratema.org.br/CustoHorario/Tabela>. Acesso em: 8 nov. 2016.

Banco Central do Brasil [BCB]. 2017. Histórico das taxas de juros: histórico das taxas de juros fixadas pelo Copom e evolução da taxa Selic. Disponível em:

<https://www.bcb.gov.br/Pec/Copom/Port/taxaSelic.asp>. Acesso em: 29 mar. 2017.

Banco Nacional do Desenvolvimento [BNDES]. 2016. Simulador. Disponível em: <http://www.bndes.gov.br/wps/portal/site/home/financiamento/simulador/?productCode =DESAG_012>. Acesso em: 4 nov. 2016.

Bendlin, L.; Souza, A. 2013. Custo de produção, expectativas de retorno e de riscos do agronegócio uva niágara no planalto norte de Santa Catarina. In: XX Congresso Brasileiro de custos, 2013, Porto de Galinhas. Anais do XX Congresso Brasileiro de custos. Disponível em: <https://anaiscbc.emnuvens.com.br/anais/article/view/22/22>. Acesso em: 15 nov. 2016.

Botton, M.; Maia, J.D.G.; Specht, A.; Machota Jr, R.; Zenker, M.M. 2012. Pragas da uva Niágara no Brasil. p. 229-251. In: Maia, J.D.G.; Camargo, U.A. O cultivo da videira Niágara no Brasil. Embrapa, Brasília, Distrito Federal, Brasil.

Cato, S.C.; Terra, M.M.; Botelho, R.V.; Tecchio, M.A.; Paioli-Pires, E.J.; Carvalho, C.R.L.; Piedade, S.M.S. 2005. Características morfológicas dos cachos e bagas de uva 'Niagara Rosada' (Vitis Labrusca L.) tratadas com o ácido giberélico e anelamento. Acta Scientiarum 27: 177-181.

Centro de Pesquisas Meteorológicas e Climáticas Aplicadas à Agricultura [CEPAGRI]. 2016. Clima dos Municípios Paulistas: Piracicaba. Disponível em: <http://www.cpa.unicamp.br/outras-informacoes/clima_muni_436.html>. Acesso em: 01 nov. 2016.

Companhia Paulista de Força e Luz [CPFL Energia]. 2016. Taxas e tarifas. Disponível em: <http://servicosonline.cpfl.com.br/servicosonline/taxasetarifas/taxasetarifas.aspx>. Acesso em: 10 nov. 2016.

Empresa Brasileira de Pesquisa Agropecuária [EMBRAPA]. 2003. Cultivo da videira 'Niagara Rosada' em regiões tropicais do Brasil. Disponível em: <http://sistemasdeproducao.cnptia.embrapa.br/FontesHTML/Uva/UvaNiagaraRosadaR egioesTropicais/>. Acesso em: 25 out. 2016.

Empresa Brasileira de Pesquisa Agropecuária [EMBRAPA]. 2010. Cultivo da videira. Disponível em:

<http://www.cpatsa.embrapa.br:8080/sistema_producao/spuva/comercializacao.html>. Acesso em: 22 mar. 2017.

Empresa Brasileira de Pesquisa Agropecuária [EMBRAPA]. 2013a. Vitivinicultura brasileira: panorama 2012. (Comunicado Técnico Embrapa 137). Disponível em: <http://www.cnpuv.embrapa.br/publica/comunicado/cot137.pdf>. Acesso em: 15 out. 2016. 
Empresa Brasileira de Pesquisa Agropecuária [EMBRAPA]. 2013b. Sistemas de condução da videira. Disponível em:

<http://www.cnpuv.embrapa.br/publica/sprod/viticultura/espald.html>. Acesso em: 27 out. 2016.

Frizzone, J.A.; Andrade Júnior, A.S. 2005. Planejamento de irrigação: Análise de decisão e investimentos. Embrapa Informação Tecnológica, Brasília, Distrito Federal, Brasil.

HF Brasil. 2017. Banco de dados: preços médios dos hortifrutícolas. Disponível em: $<$ http://www.hfbrasil.org.br/br/banco-de-dados-precos-medios-doshortifruticolas.aspx>. Acesso em: 01 mar. 2017.

Instituto Brasileiro de Geografia e Estatística [IBGE]. 2016a. Levantamento sistemático da produção agrícola: pesquisa mensal de previsão e acompanhamento das safras agrícolas no ano civil. Disponível em:

<ftp://ftp.ibge.gov.br/Producao_Agricola/Levantamento_Sistematico_da_Producao_Agr icola_\%5Bmensal\%5D/Fasciculo/lspa_201601.pdf>. Acesso em: 20 out. 2016.

Instituto Brasileiro de Geografia e Estatística [IBGE]. 2016b. Séries históricas: IPCA. Disponível em:

<http://www.ibge.gov.br/home/estatistica/indicadores/precos/inpc_ipca/defaultseriesHis t.shtm>. Acesso em: 25 out. 2016.

Instituto de Economia Agrícola [IEA]. 2017. Estatísticas da Produção Paulista. Disponível em: <http://ciagri.iea.sp.gov.br/nia1/subjetiva.aspx?cod_sis=1\&idioma=1>. Acesso em: 26 mar. 2017.

Keller, M. 2010. The science of grapevines: anatomy and physiology. 1ed. Elsevier, San Diego, California, EUA.

Kreuz, C.L.; Souza, A.; Schuck, Ê.; Petri, J.L. 2005. Avaliação econômica de alternativas de investimento no agronegócio da uva no Meio Oeste Catarinense. Revista Brasileira de Fruticultura 27: 230-237.

Maia, J.D.G.; Camargo, U.A. 2012. Implantação do vinhedo. p.31-79. In: Maia, J.D.G.; Camargo, U.A. O cultivo da videira Niágara no Brasil. Embrapa, Brasília, Distrito Federal, Brasil.

Manica, I.; Pommer, C.V. 2006. Uva: do plantio a produção, pós-colheita e mercado. Editora Cinco Continentes, Porto Alegre, Rio Grande do Sul, Brasil.

Mendonça, T.G. de; Lírio, V.S.; Moura, A.D.; Reis, B.S.; Silveira, S.F.R. 2009. Avaliação da viabilidade econômica da produção de mamão em sistema convencional e de Produção Integrada de Frutas (PIF). Revista Econômica do Nordeste. 40(1): 699723. Disponível em:

<http://www.bnb.gov.br/projwebren/Exec/artigoRenPDF.aspx?cd_artigo_ren=1160>. Acesso em: 26 mar. 2017.

Miele, A.; Mandelli, F. 2008. Instalação do vinhedo. p.57-72. In: Nachtigal, J.C., Mazzarolo, A. Uva: o produtor pergunta, a Embrapa responde. Embrapa Informação Tecnológica, Brasília, Distrito Federal, Brasil. 
Naves, R.L.; Garrido, L.R.; Fajardo, T.V.M. 2012. Doenças da videira causadas por fungos, vírus e bactérias. p. 187-228. In: Maia, J.D.G.; Camargo, U.A. O cultivo da videira Niágara no Brasil. Embrapa,Brasília, Distrito Federal, Brasil.

Núcleo de Monitoramento Agroclimático [NURMA]. 2016. Disponível em: <http://www.esalq.usp.br/departamentos/leb/bhbrasil/Saopaulo/>. Acesso em: 3 nov. 2016.

Oliveira, M.D.M.; Silva, P.R.; Amaro, A.A.; Tecchio, M.A. 2008. Viabilidade econômica em tratamento antidegrana em uva "Niagara Rosada" no Estado de São Paulo. Informações Econômicas 38: 59-67.

Reis, L.P.; Reis, P.C.M. 2016. Viabilidade econômica do cultivo de uva irrigada no município de Petrolina, PE. Enciclopédia Biosfera 13: 1989-1099.

Silva, P.R.; Maia, M.L.; Amaro, A.A.; Oliveira, M.D.M.; Terra, M.M. 2008. Produção e comercialização de uva niagara nas regiões de Campinas e Jales, Estado de São Paulo. Informações Econômicas 38: 61-72.

Silva, P.R.; Verdi, A.R.; Francisco, V.L.F.S.; Baptistella, C.S.L. 2006. Tradição do cultivo da uva niagara no Estado de São Paulo. Informações Econômicas 36: 33-42.

Tecchio, M.A.; Terra, M.M.; Maia, J.D.G. 2012. Nutrição, calagem e adubação da videira Niágara. p.137-173. In: Maia, J.D.G.; Camargo, U.A. O cultivo da videira Niágara no Brasil. Embrapa, Brasília, Distrito Federal, Brasil.

Terra, M.M.; Pires, E.J.P.; Pommer, C.V.; Botelho, R.V. 2003. Produtividade da cultivar de uva de mesa Niagara Rosada sobre diferentes porta-enxertos, em Monte Alegre do Sul-SP. Revista Brasileira de Fruticultura 25: 549-551. 